\title{
Measurement Uncertainty and Representation of Tensile Mechanical Properties in Metals
}

\author{
Tingdong $\mathrm{Xu}{ }^{1, *}$, Kai Wang ${ }^{1}$ and Shenhua Song ${ }^{2, *}$ \\ 1 Central Iron \& Steel Research Institute, Beijing 100081, China; wangkai483@aliyun.com \\ 2 Harbin Institute of Technology, School of Materials Science and Engineering, Shenzhen 518055, China \\ * Correspondence: xutingd2021@hotmail.com (T.X.); shsong@hit.edu.cn (S.S.)
}

Citation: Xu, T.; Wang, K.; Song, S.

Measurement Uncertainty and

Representation of Tensile Mechanical Properties in Metals. Metals 2021, 11, 1733. https://doi.org/10.3390/ met11111733

Academic Editors: Frank Czerwinski and Evangelos Hristoforou

Received: 7 June 2021

Accepted: 26 October 2021

Published: 29 October 2021

Publisher's Note: MDPI stays neutral with regard to jurisdictional claims in published maps and institutional affiliations.

Copyright: (c) 2021 by the authors. Licensee MDPI, Basel, Switzerland. This article is an open access article distributed under the terms and conditions of the Creative Commons Attribution (CC BY) license (https:// creativecommons.org/licenses/by/ $4.0 /)$.

\begin{abstract}
The International Organization for Standardization Technical Committee for Metallic Materials-Tensile Testing stated in 2011 that temperature and strain rate variations would induce a change in the results of tensile tests, termed as the measurement uncertainty of tensile mechanical properties in metals. The uncertainty means that the tensile testing results of a specimen at a temperature and strain rate are not the original mechanical properties possessed prior to the testing. Hence, since the time of Galileo the results of tensile testing have been incorrectly interpreted as the original mechanical properties of specimens, thereby forming a paradox. At the turn of the 21st century, the micro-theory of metallic elastic deformation was proposed, identifying that a change in microstructure at atomic level could occur during elastic deformation, leading to a change in the concentration of solute (impurity) at grain boundaries/around dislocations. The micro-theory has been used to explain the mechanism of the measurement uncertainty. Different tensile temperatures and strain rates correspond to different durations of elastic deformation during tensile testing, different concentrations of solute at grain boundaries/dislocations, and thus different mechanical properties. On this basis, a new technology system of tensile testing is suggested, i.e., a "mechanical property-tensile strain rate" curve at a given test temperature can be used to evaluate the original mechanical property. The higher the strain rate is, the closer the property on the curve is to the original property. Therefore, to determine the original mechanical property of the tested metal, a sufficiently high strain rate is required. The curve can also characterize the property variation of the tested metal in service with the service time. In addition, the property characterized by a point on the curve can represent the property of the tested metal when processing-deformed with the corresponding strain rate. As an example of the application of the new technology system, the property of high-entropy alloys is represented with a curve. The results show that the new technology system could change the conceptual framework and testing technology system of metallic mechanics.
\end{abstract}

Keywords: measurement uncertainty; mechanical properties; metals; embrittlement; grain boundary segregation; ductility

\section{Introduction}

The tensile test, as a measurement system, is used to evaluate the strength and ductility of metals and alloys. In this test system, a metal sample is pulled to failure in a relatively short time at a constant strain rate. The mechanical properties of metals and alloys which are of engineering importance for structural design and can be obtained from the tensile test system include the modulus of elasticity, yield strength, ultimate tensile strength, elongation, and reduction in area. The standard test methods for the elevated temperature tension test of metallic materials were originally approved by ASTM international in 1933 [1]. In 1947, the International Organization for Standardization (ISO) also established a relative technical standard for the elevated temperature tension test of metallic materials [2]. Since then, these standards have been subject to revision from time to time by the responsible technical committee and reviewed every five years, and if 
not revised, either re-approved or withdrawn. However, for this important measurement system, it was pointed out in 2011 by the Technical Committee Mechanical Testing of Metals (ISO/TC164) that the variations in temperature and strain rate in tensile testing had been found to exhibit an apparent effect on the results, contributing uncertainty unrelated to the test equipment. The uncertainty of the test results can be related to both test equipment and temperature/strain rate. The uncertainty contribution related to test equipment may be derived from the calibration certificates for the devices used for the determination of the test results (see ISO 6892-1:2009, J.3). However, the uncertainty components associated with test temperature and strain rate variations, i.e., the effect of strain rate/temperature, must be determined experimentally since these uncertainties are highly material dependent. Therefore, the uncertainty components relative to temperature and strain rate variations should be considered when estimating the measurement uncertainty of testing results [2]. ISO/TC164 used Figures 1 and 2 to show the measurement uncertainty relative to temperature and strain rate variations. As shown in Figure 1, at different temperatures under a fixed strain rate, there are large differences in the material response. There are also large differences in the material response under different strain rates at a fixed temperature (see Figure 2).

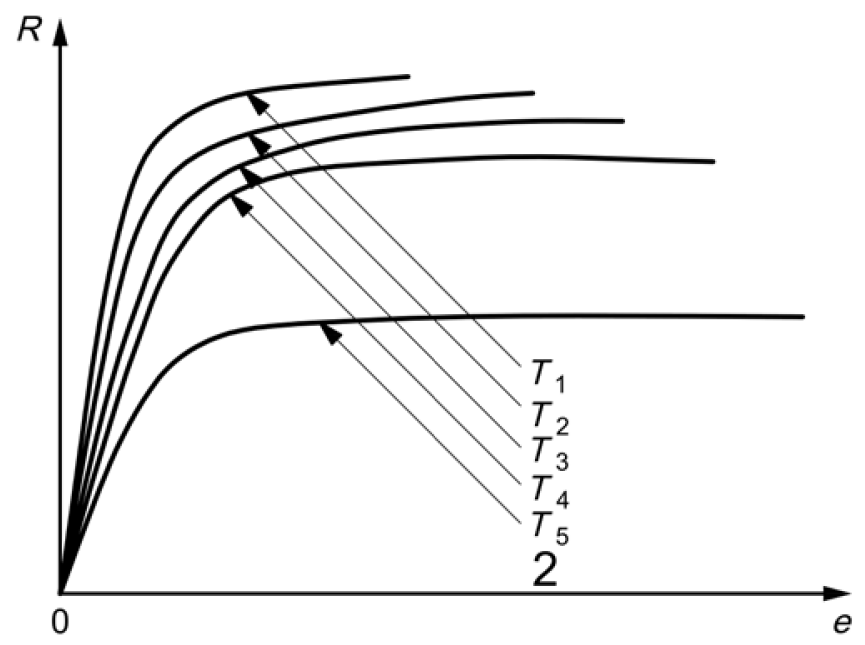

Figure 1. Stress-strain curves at a given strain rate and different temperatures ( $R$ : stress/MPa; $e$ : strain/\%; temperature: $T_{1}<T_{2}<T_{3}<T_{4}<T_{5}$ ). Reprinted from ref. [2].

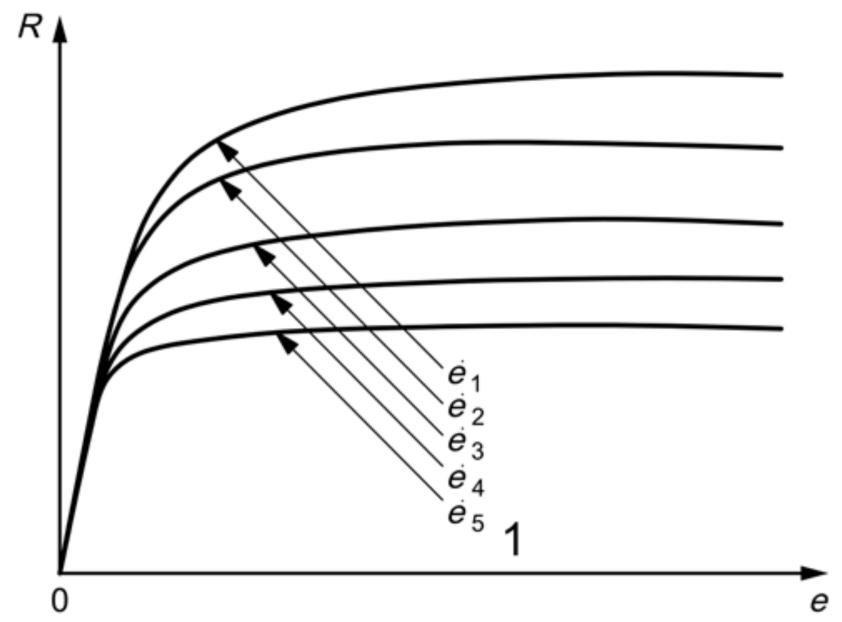

Figure 2. Stress-strain curves at $850{ }^{\circ} \mathrm{C}$ and different strain rates (R: stress/MPa; $e$ : strain/\%; strain rate: $\dot{e}_{1}>\dot{e}_{2}>\dot{e}_{3}>\dot{e}_{4}>\dot{e}_{5}$ ). Reprinted from ref. [2]. 
Figures 1 and 2 indicate that, for a metal, after undergoing a given thermal cycle, the variations in temperature and strain rate in tensile testing can alter the stress-strain curve, leading to a large difference in testing results. Such a difference occurs during the process of tensile testing and is not an expression of the original properties of tested metals. The Technical Committee Mechanical Testing of Metals (ISO/TC164) has named such a difference as measurement uncertainty of mechanical properties relative to temperature and strain rate variations in the tension test system, which includes the uncertainties in the modulus of elasticity, yield strength, ultimate tensile strength, percent elongation at fracture, and percent reduction in area at fracture [2]. It pointed out that the uncertainty of the test results influenced by temperature and strain rate variations must be determined experimentally since the uncertainty values are highly material-dependent. For this reason, it is currently impossible to assign a set of pre-determined values of temperature and strain rate to be used for a sample to measure its original mechanical property possessed prior to testing by tensile test [2]. Hence, the present tensile test system lacks the parameterization of temperature and strain rate in testing, causing erroneous measurement of the original mechanical properties of tested metals and thereby imperiling the reliability of tension test system. It is clear that the measurement uncertainty of mechanical properties in the tensile test system suggested by this committee weakens the experimental basis of metallic mechanics.

\section{Experimental Observations of Measurement Uncertainty}

Figures 1 and 2 only show that the measurement uncertainty of mechanical properties can be produced by variations in temperature and strain rate in the tensile test system. However, the underlying mechanism for this phenomenon is still unclear. The measurement uncertainty in the reduction of area relative to variations in temperature and strain rate will be described experimentally below in order to suggest a mechanism for the measurement uncertainty.

\subsection{Uncertainty Relative to Temperature: Intermediate Temperature Embrittlement}

Figure 3 shows the tensile test results by Sun et al. [3,4] with five strain rates at different temperatures for an $\mathrm{Fe}-17 \mathrm{Cr}$ steel. It is shown that, for each strain rate, the reduction of area varies with testing temperature, exhibiting a measurement uncertainty relative to temperature. Furthermore, for each strain rate, there is an intermediate temperature at which embrittlement reaches a maximum (a minimum reduction in area) $[3,4]$. This temperature decreases with decreasing strain rate.

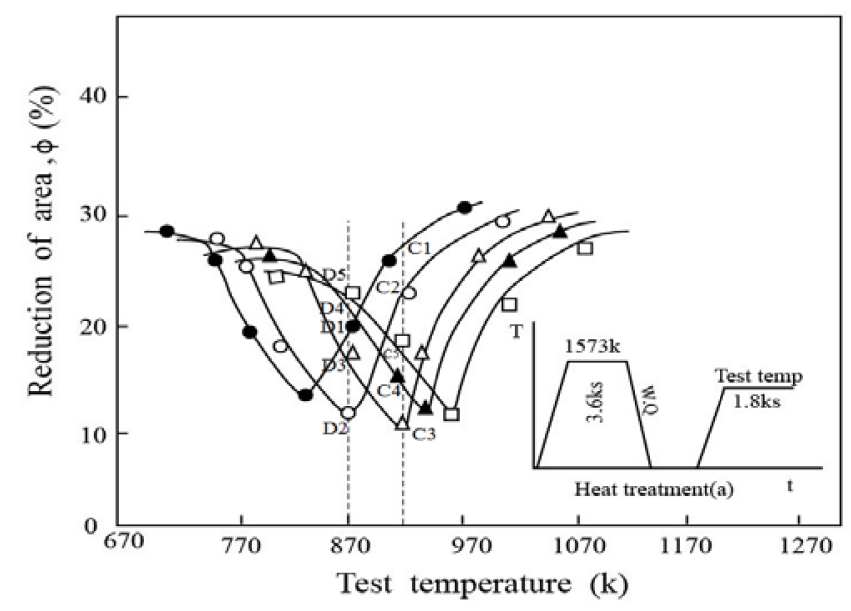

Figure 3. Variation in reduction of area with temperature and strain rate for an Fe-17Cr steel after heat treatment as shown in inset $\left(\bullet: \dot{\varepsilon}=1.43 \times 10^{-5} \mathrm{~s}^{-1}, \bigcirc: \dot{\varepsilon}=1.43 \times 10^{-4} \mathrm{~s}^{-1}, \triangle: \dot{\varepsilon}=1.43 \times 10^{-3} \mathrm{~s}^{-1}\right.$, $\mathbf{\Delta}: \dot{\varepsilon}=1.43 \times 10^{-2} \mathrm{~s}^{-1}$, and $\square: \dot{\varepsilon}=1.43 \times 10^{-1} \mathrm{~s}^{-1}$ ). Reprinted with permission from ref. [4]. Copyright 1969 Springer Nature. 
Figure 4 represents the tension test results by Otsuka et al. [5], with five strain rates at different temperatures for an Al-5 wt\%Mg alloy. As in the case of Fe-17Cr steel, for each strain rate, the reduction of area varies with testing temperature, also exhibiting a measurement uncertainty relative to temperature. Again, for each strain rate, there is an intermediate temperature at which embrittlement reaches a maximum (a minimum reduction in area). This temperature also decreases with decreasing strain rate.

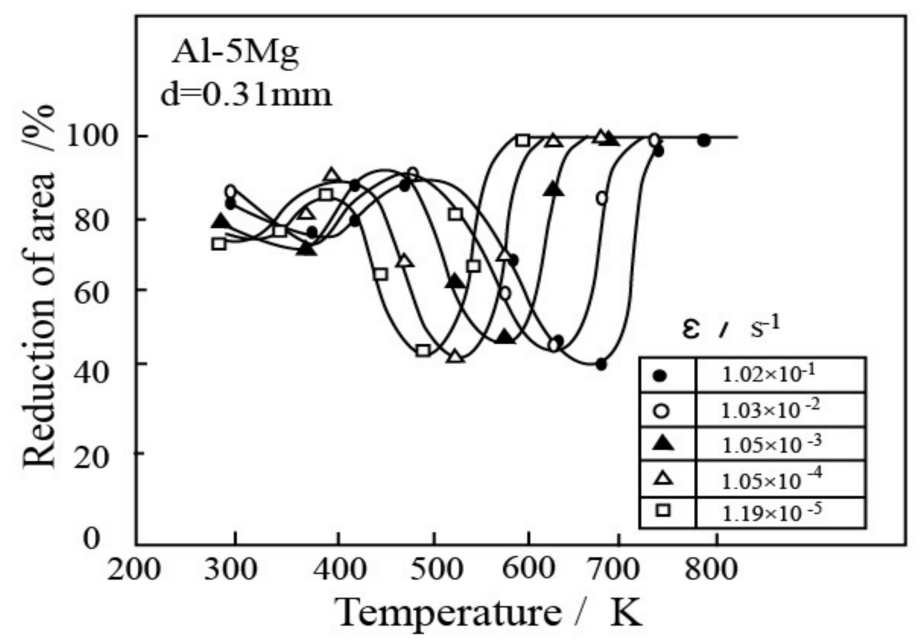

Figure 4. Reduction of area versus test temperature for Al-5 $\mathrm{wt}_{\mathrm{t}} \mathrm{\textrm {Mg }}$ alloy after deformation with various strain rates ranging from $\dot{\varepsilon}=1.02 \times 10^{-1} \mathrm{~s}^{-1}$ to $\dot{\varepsilon}=1.19 \times 10^{-5} \mathrm{~s}^{-1}$. Reprinted from ref. [5].

Figure 5 shows the test results by Nowosielski et al. [6] for a CuNi25 alloy. They also show the existence of the measurement uncertainty relative to temperature in the intermediate temperature embrittlement. When varying strain rate. there is a temperature for each strain rate at which the embrittlement attains a maximum. This temperature decreases with decreasing strain rate.

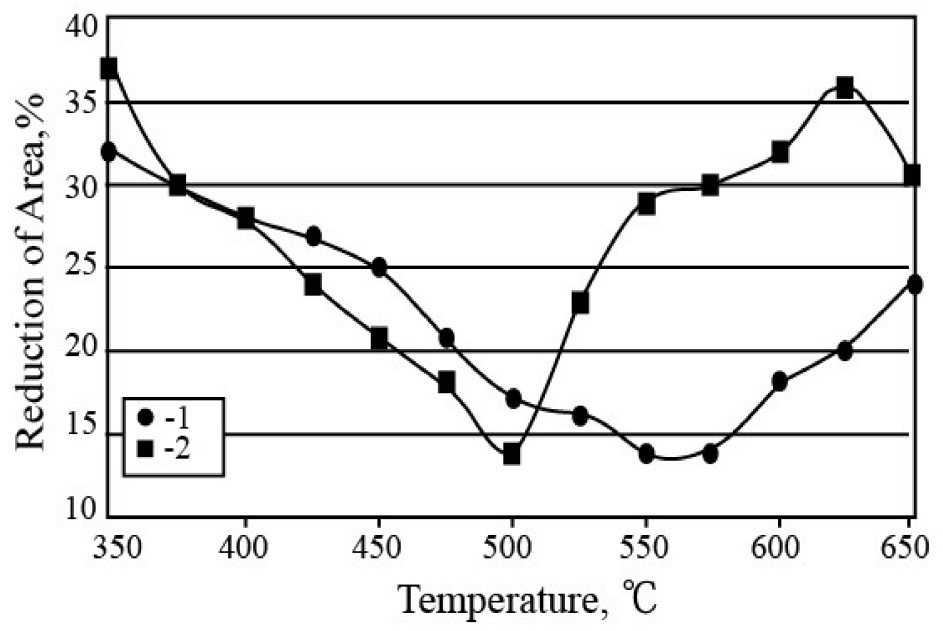

Figure 5. Reduction of area versus test temperature for a CuNi25 alloy after deformation with strain rates: $1 . \dot{\varepsilon}=2.7 \times 10^{-1} \mathrm{~s}^{-1}$ and $2 . \dot{\varepsilon}=2.7 \times 10^{-3} \mathrm{~s}^{-1}$. Reprinted from ref. [6].

When a metal, after undergoing a given thermal cycle, is tensile tested at different temperatures with a fixed strain rate, as shown in Figures 3-5, its reduction of area varies with temperature, and there is a temperature at which the reduction of area reaches a minimum (maximum embrittlement). This is the intermediate temperature embrittlement in metals [7]. Apparently, the intermediate temperature embrittlement of metals is a kind of measurement uncertainty in the reduction of area relative to temperature variation in 
the tensile test system, suggested by Technical Standard ISO6892-2-2011. This uncertainty should result from disturbance by the testing temperature, being an essential factor in the tensile testing system itself. In 1877, the intermediate temperature embrittlement was first discovered in $\mathrm{Cu}$ alloys. Since then, its mechanism has been a key issue in materials science and engineering [8]. It is clear that the intermediate temperature embrittlement is not the intrinsic property of tested metals and occurs during the process of tension testing. Therefore, its mechanism should be sought from each stage of the tensile testing system. It has been pointed out for the first time in Ref. [7] that the intermediate temperature embrittlement is produced because of the performance of the tension testing system.

The measurement uncertainty in the reduction of area relative to temperature or the intermediate temperature embrittlement, mentioned above, has the following experimental characteristics:

(1) Reduction of area varies with testing temperature for a given strain rate.

(2) There is a testing temperature at which the reduction of area reaches a minimum.

(3) The testing temperature corresponding to the minimum reduction of area shifts to lower temperatures with decreasing strain rate.

\subsection{Uncertainty Relative to Strain Rate: Strain Rate Embrittlement}

Figure 6 shows the results of tension tests by Suzuki at $1373 \mathrm{~K}$ with different strain rates for an Fe-36Ni alloy doped with $\mathrm{Cu}$ [9]. Clearly, the reduction of area varies with strain rate, being a kind of measurement uncertainty, termed as the strain rate embrittlement [10]. There is a strain rate at which the reduction of area has a minimum value, which is a critical strain rate.

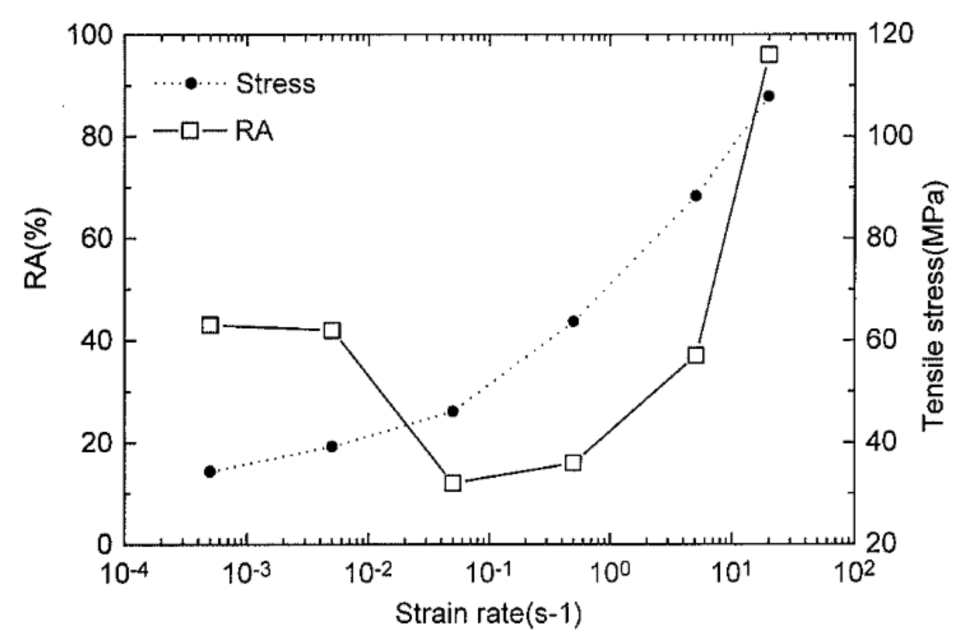

Figure 6. Reduction of area (RA) as a function of strain rate, showing strain rate embrittlement, measured at $1373 \mathrm{~K}$ for an Fe-36Ni alloy doped with $\mathrm{Cu}$. Reprinted from ref. [9].

Figure 7 is plotted according to Figure 3, displaying a modified form of experimental results for an $\mathrm{Fe}-17 \mathrm{Cr}$ steel [3,4]. As can be seen, the reduction of area of the steel varies with strain rate when tensile-tested with five strain rates at temperatures $923 \mathrm{~K}$ and $873 \mathrm{~K}$, respectively, as a form of measurement uncertainty relative to strain rate. For each temperature, there is a critical strain rate at which the reduction of area reaches a minimum value. When the testing temperature decreases from $923 \mathrm{~K}$ to $873 \mathrm{~K}$, the critical strain rate also decreases from $1.43 \times 10^{-3} \mathrm{~s}^{-1}$ to $1.43 \times 10^{-4} \mathrm{~s}^{-1}$. For the experimental results of the Al-5 $\mathrm{wt} \% \mathrm{Mg}$ alloy in Figure 4, this phenomenon in the reduction of area can be also observed at certain temperatures, such as $500 \mathrm{~K}$ and $600 \mathrm{~K}$. This means that the reduction of area for the $\mathrm{Al}-5 \mathrm{wt} \% \mathrm{Mg}$ alloy varies with strain rate and there is a strain rate at which the reduction of area possesses a minimum value. At the same time, such a strain rate is reduced when tested at a lower temperature. 


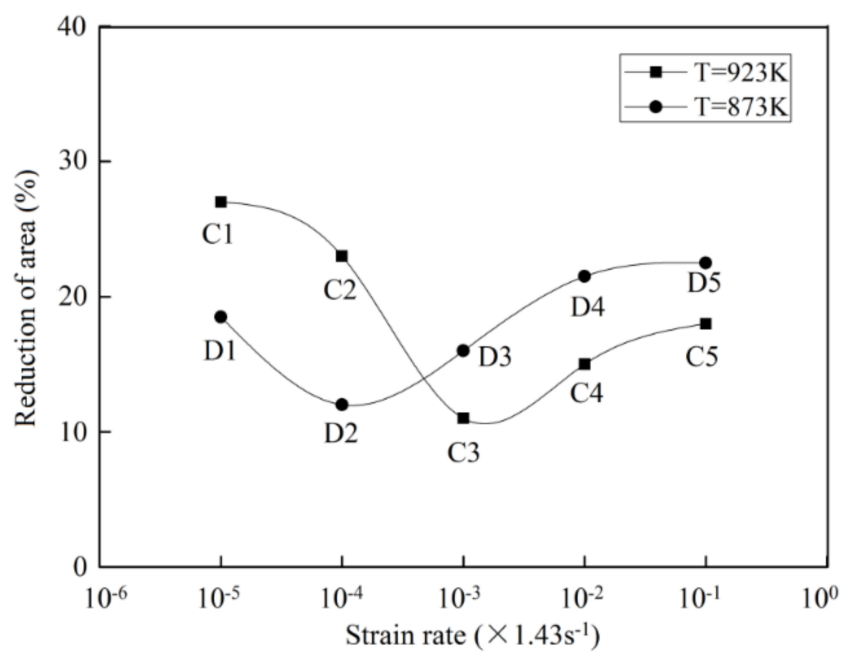

Figure 7. Reduction of area (RA) as a function of strain rate for an $\mathrm{Fe}-17 \mathrm{Cr}$ steel determined at $923 \mathrm{~K}(\mathrm{C})$ and $873 \mathrm{~K}(\mathrm{D})$ after Figure 3, showing strain rate embrittlement ((1) $\dot{\varepsilon}=1.43 \times 10^{-5} \mathrm{~s}^{-1}$, (2) $\dot{\varepsilon}=1.43 \times 10^{-4} \mathrm{~s}^{-1}$, (3) $\dot{\varepsilon}=1.43 \times 10^{-3} \mathrm{~s}^{-1}$, (4) $\dot{\varepsilon}=1.43 \times 10^{-2} \mathrm{~s}^{-1}$, and (5) $\dot{\varepsilon}=1.43 \times 10^{-1} \mathrm{~s}^{-1}$, plotted from the data in Figure 3). Adapted from ref. [4].

Figure 8 displays the results of tension tests by Nagasaki et al. [11] for a C-Mn steel with $S$ as impurity at three temperatures with different strain rates. The variation in the reduction of area with strain rate indicates the measurement uncertainty relative to strain rate, i.e., the strain rate embrittlement. There is a critical strain rate, between $10^{-1} \mathrm{~s}^{-1}$ and $1 \mathrm{~s}^{-1}$ at $1173 \mathrm{~K}$, at which the reduction of area (RA) exhibits a minimum value. At two higher temperatures, $1273 \mathrm{~K}$ and $1423 \mathrm{~K}$, the reduction of area decreases with increasing strain rate for both cases, and the curve of the RA-strain rate at the higher temperature $1423 \mathrm{~K}$ is above that at the lower temperature $1273 \mathrm{~K}$.

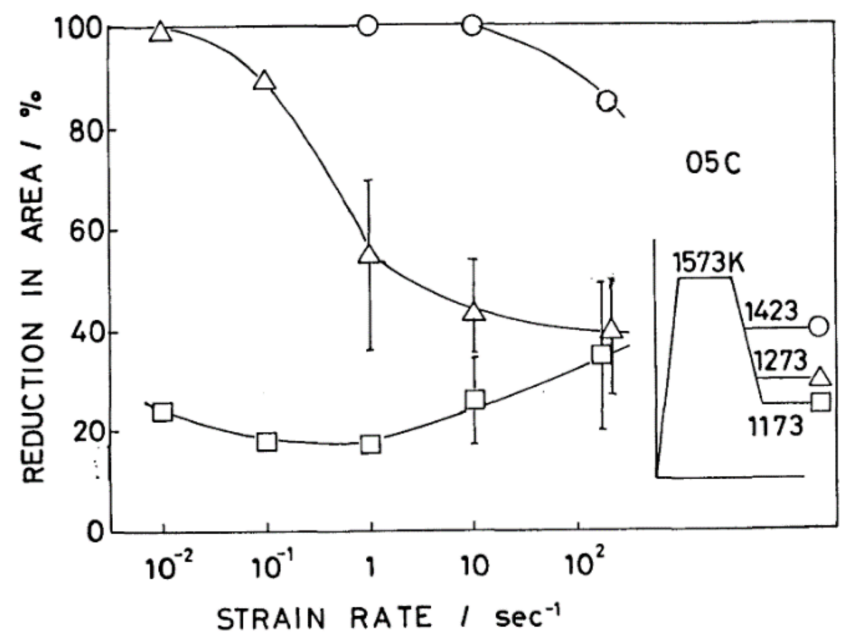

Figure 8. Strain rate dependence of hot ductility at different test temperatures for a C-Mn steel with $\mathrm{S}$ as impurity. Reprinted from ref. [11].

For a C-Mn steel doped with $\mathrm{Cu}$, the variation in the reduction of area with strain rate when testing at different temperatures is shown in Figure 9 [9]. A measurement uncertainty relative to strain rate, i.e., the strain rate embrittlement, can also be seen. As shown in Figure 9, the reduction of area increases with increasing strain rate for all cases, and the curve of the RA-strain rate at the lower temperature is above that at the higher temperature. These results are opposite to those in Figure 8. 


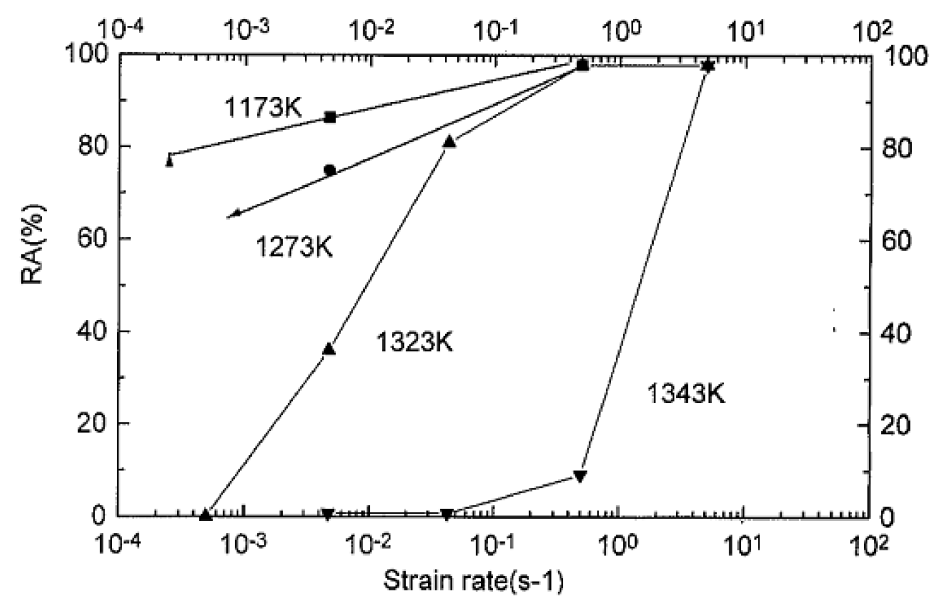

Figure 9. Strain rate dependence of hot ductility at different test temperatures for a C-Mn steel with $\mathrm{Cu}$ as impurity. Reprinted from ref. [9].

Figures 10 and 11 show the variation in the elongation with strain rate obtained by Kumar and Peng [12] for an Fe-40Al-0.6C alloy at $-30{ }^{\circ} \mathrm{C}$, room temperature, and $700{ }^{\circ} \mathrm{C}$, respectively. A measurement uncertainty relative to strain rate is clearly shown. Figure 10 is similar to Figure 9, in that the embrittlement decreases (the elongation increases) with increasing strain rate, and the curve of the elongation-strain rate at the lower temperature $\left(-30^{\circ} \mathrm{C}\right)$ is above that at higher temperature (room temperature). However, the variation in the elongation with strain rate at $700{ }^{\circ} \mathrm{C}$, as shown in Figure 11, is opposite to that at $-30{ }^{\circ} \mathrm{C}$, or room temperature, although the alloy samples were subjected to an identical thermal cycle prior to testing. At $700{ }^{\circ} \mathrm{C}$, the elongation decreases with increasing strain rate.

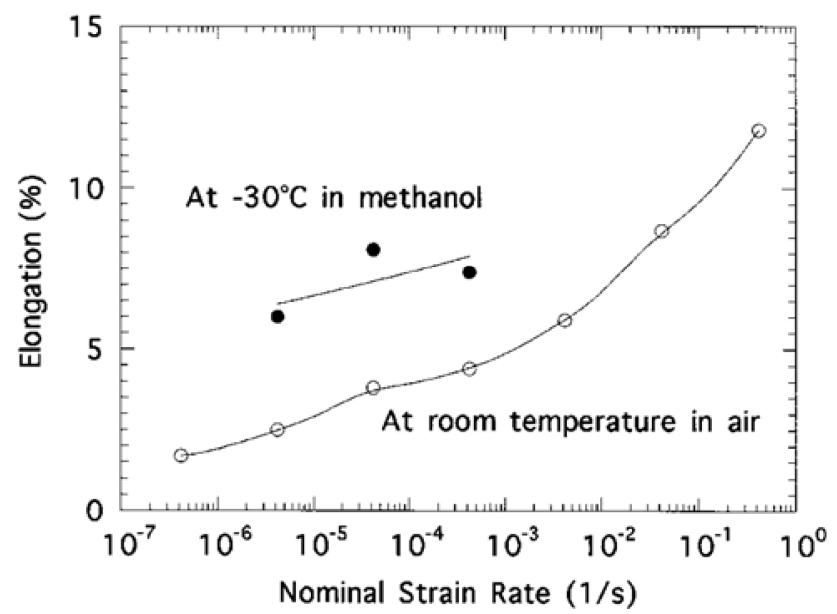

Figure 10. The effect of strain rate on ductility at room temperature and $-30{ }^{\circ} \mathrm{C}$, respectively, for an extruded low-temperature annealed Fe-40Al-0.6C alloy. Reprinted with permission from ref. [12]. Copyright 1998 Elsevier. 


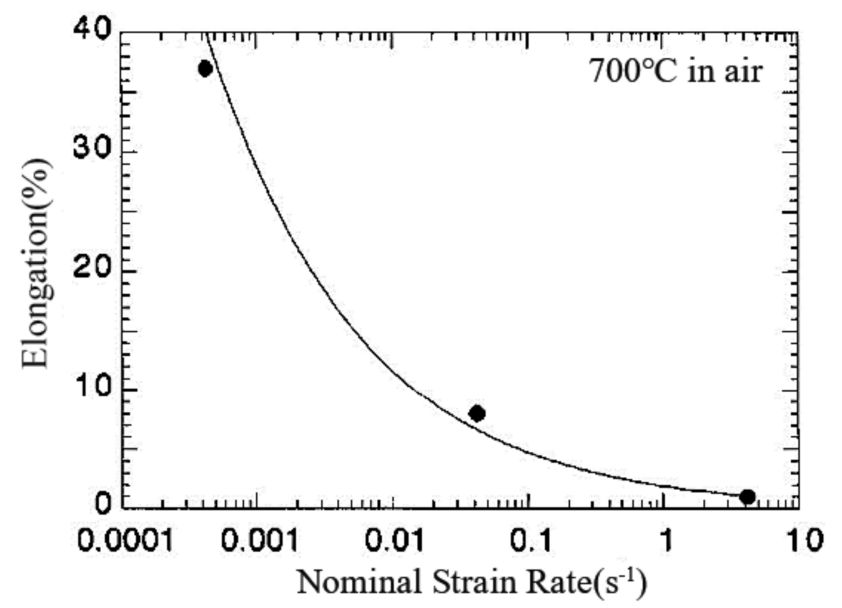

Figure 11. The effect of test strain rate on ductility at $700{ }^{\circ} \mathrm{C}$ for an extruded low-temperature annealed Fe-40Al-0.6C alloy. Reprinted with permission from ref. [12]. Copyright 1998 Elsevier.

For an alloy that is subjected to a given thermal cycle and subsequently tensiletested at a certain temperature with different strain rates, as shown in Figures 6-11, its reduction of area or elongation varies with strain rate. This is a phenomenon of strain rate embrittlement. At each testing temperature, there is usually a strain rate at which the reduction of area reaches a minimum value. The strain rate embrittlement is the measurement uncertainty in the reduction of area relative to strain rate, suggested by the technical standard ISO 6892-2-2011 [10]. This measurement uncertainty should arise from the disturbance by strain rate, which is an essential factor of the tensile test system. It is envisaged that the mechanism of such a measurement uncertainty may be found from the effect of strain rate variation during tensile testing.

The characteristics of the measurement uncertainty relative to strain rate in the tensile test of alloys may be summarized from Figures 6-11 as follows.

(1) The change in strain rate can cause a variation in the reduction of area or elongation when tensile-tested at a fixed temperature, termed the strain rate embrittlement.

(2) There is usually a strain rate at which a maximum embrittlement occurs, termed the critical strain rate.

(3) The critical strain rate decreases with the decrease in test temperature.

(4) For the case with no critical strain rate present, the reduction of area may increase or decrease continuously with increasing strain rate. When the reduction of area decreases with strain rate, the curve of the RA-strain rate at a higher temperature is always above that at a lower temperature. Nevertheless, when the reduction of area increases with strain rate, the curve of the RA-strain rate (or elongation-strain rate) at a lower temperature is always above that at a higher temperature.

(5) For an alloy that undergoes a given thermal cycle, the reduction of area may increase or decrease with strain rate when tensile-tested at different temperatures.

\subsection{Tensile Testing Results of Pure Metals}

Each specimen is in a certain condition before testing and must have a certain set of mechanical properties, termed as the original mechanical properties. The measurement uncertainty makes the testing results somewhat different from the original mechanical properties of the specimen, which can be seen from Figures 6-11 [10]. For pure metals, can the testing results be their original properties? This will be discussed below.

The experimental results by Knaai and Floreen [13] demonstrate that when the content of impurity $\mathrm{S}$ is $0 \mathrm{ppm}$ the intermediate temperature embrittlement does not occur for $\mathrm{Ni}$, and the RA does not obviously vary with test temperature. When the $S$ content is $5 \mathrm{ppm}$ or above, the intermediate temperature embrittlement takes place more obviously. Hence, the 
$\mathrm{RA}$ of Ni containing $0 \mathrm{ppm} \mathrm{S}$ is the original RA of pure Ni. Nevertheless, for Ni containing a small amount of $S$, it is difficult to determine its original mechanical property.

Liu et al. [14] have confirmed that there is no intermediate temperature embrittlement during tensile testing for high-purity Fe containing less than 2 ppm S, as shown in Figure 12. The high-purity Fe displays excellent ductility, and the RA almost does not change with changing test temperature between 673 and $1173 \mathrm{~K}$. The intermediate temperature brittleness occurs when the Fe contains more than 5 ppm S (Fe-5s, Fe-10S, Fe-20S and Fe-80S alloys in Figure 12). Its hot ductility deteriorates significantly in the intermediate temperature range, and the RA varies with test temperature. Therefore, the original mechanical properties of pure Fe can be obtained when containing less than 2 ppm S, but not when containing more than $5 \mathrm{ppm}$.

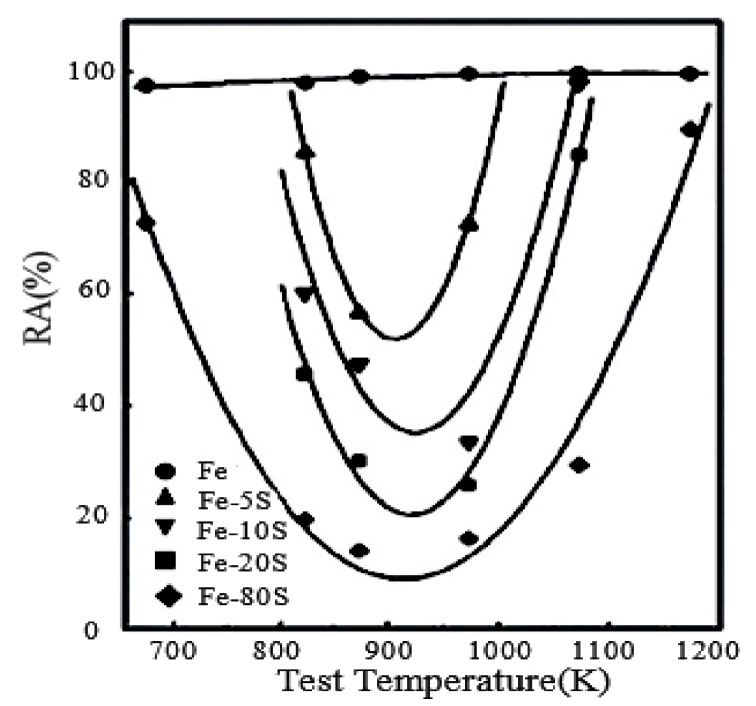

Figure 12. Variation of RA with test temperature for Fe with different levels of $S$ in ppm. Reprinted with permission from ref. [14]. Copyright 1999 Acta Metallurgica Sinica (English Letters).

As demonstrated by Horikawa et al. [15], the impurity Na has a large effect on the hot ductility of an Al-5Mg alloy when testing at a given strain rate, as shown in Figure 13. When the alloy contains $1.8 \mathrm{wt}-\mathrm{ppm} \mathrm{Na}$, there is a deep ductility trough around $573 \mathrm{~K}$, i.e., the intermediate temperature embrittlement. However, when the alloy contains $0.01 \mathrm{wt}-\mathrm{ppm} \mathrm{Na}$, the intermediate temperature embrittlement does not occur, and the RA remains at an almost stable value with changing temperature. Thus, the original mechanical property of the alloy may be determined when containing $0.01 \mathrm{wt}$-ppm Na or less [15].

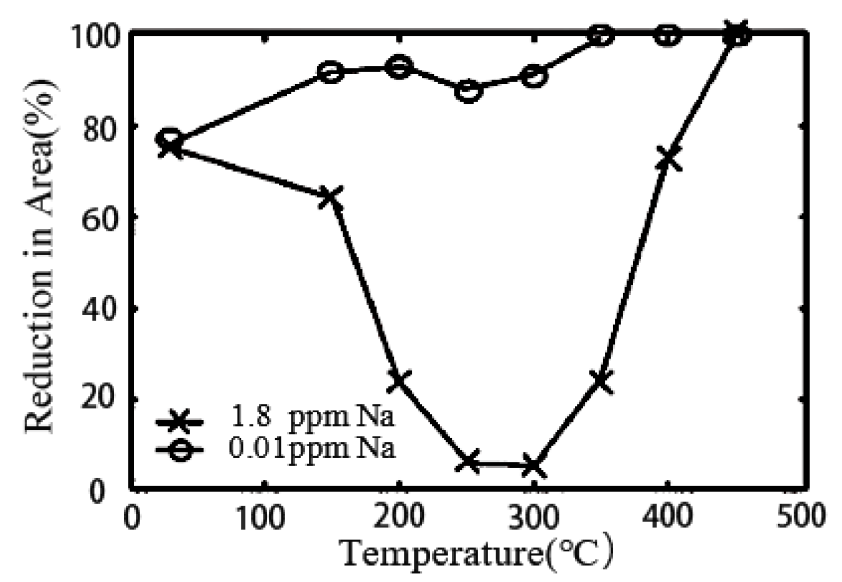

Figure 13. Variation of RA with test temperature for an Al-5Mg alloy with different contents of $\mathrm{Na}$. Reprinted with permission from ref. [15]. Copyright 2001 Elsevier. 
Nachtrab and Chou [16] tensile-tested two C-Mn steels (steel C and steel D). Their chemical compositions are listed in Table 1. The testing results are shown in Figures 14 and 15. The RA variation with test temperature at a fixed strain rate (crosshead speed: $0.13 \mathrm{~cm} / \mathrm{min}$ ) is shown in Figure 14 and the RA variation with strain rate at a fixed temperature of $900{ }^{\circ} \mathrm{C}$ in Figure 15. It is seen from Table 1 that the concentrations of impurities of $\mathrm{Cu}, \mathrm{Sb}$, and especially $S$ and $S n$ in steel $C$ is much lower than those in steel D. It is clearly shown from Figure 14 that steel $C$ has no intermediate temperature embrittlement, i.e., the RA does not vary with test temperature. In addition, steel $C$ also has no strain rate embrittlement (see Figure 15), i.e., the RA does not vary with strain rate and remains at a level of approximately $100 \%$. Nevertheless, steel D exhibits both apparent intermediate temperature embrittlement and strain rate embrittlement (see Figures 15 and 16). Consequently, it is stated that metals may simultaneously have intermediate temperature embrittlement and strain rate embrittlement. This means that if a metal has intermediate temperature embrittlement it certainly has strain rate embrittlement, and vice versa.

Table 1. Chemical composition of C-Mn steel heats C and D (wt\%). Adapted from ref. [16].

\begin{tabular}{ccccccccc}
\hline Heat & $\mathbf{C}$ & $\mathbf{M n}$ & $\mathbf{P}$ & $\mathbf{S}$ & $\mathbf{S i}$ & $\mathbf{C u}$ & $\mathbf{N i}$ & $\mathbf{C r}$ \\
\hline $\mathrm{C}$ & 0.24 & 1.06 & 0.011 & 0.002 & 0.230 & 0.110 & 0.100 & 0.055 \\
$\mathrm{D}$ & 0.19 & 1.32 & 0.009 & 0.019 & 0.218 & 0.263 & 0.203 & 0.160 \\
\hline & $\mathrm{Mo}$ & $\mathrm{As}$ & $\mathrm{Sb}$ & $\mathrm{Sn}$ & $\mathrm{Al}$ & $\mathrm{Al}_{\text {sol }}$ & $\mathrm{N}$ & \\
$\mathrm{C}$ & 0.052 & 0.0082 & 0.0013 & 0.005 & 0.046 & 0.045 & 0.0176 & \\
$\mathrm{D}$ & 0.061 & 0.0096 & 0.0035 & 0.036 & 0.036 & 0.030 & 0.0096 & \\
\hline
\end{tabular}

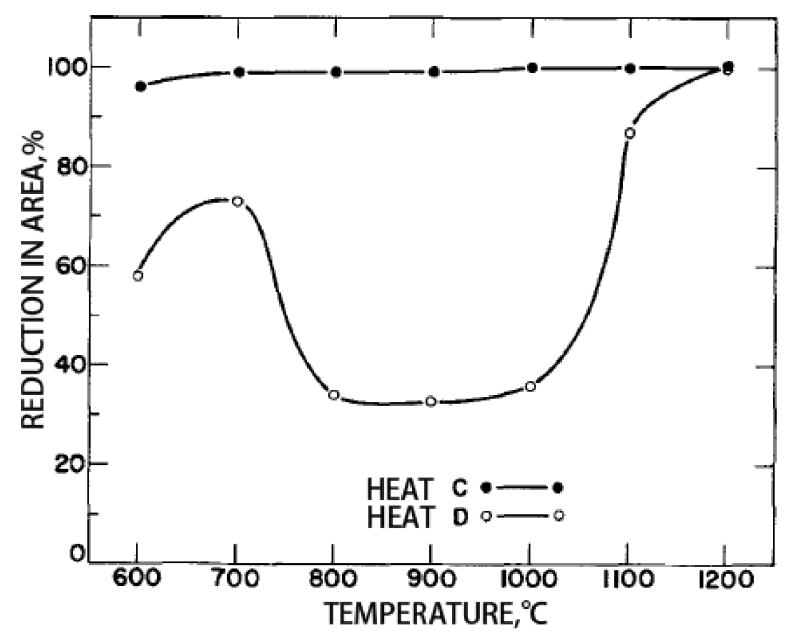

Figure 14. Effect of tensile temperature on the reduction of area for C-Mn steel heats C and D. Reprinted with permission from ref. [16]. Copyright 1969 Springer Nature.

As demonstrated above, the current tensile test technology can obtain the original mechanical properties only for very high-purity metals, which occupy a very small proportion of metallic materials. For the vast majority of metallic materials which contain more than several parts per million (ppm) of impurities, their original mechanical properties may not be obtained by the current tensile test procedure. Consequently, the current tensile test technology has been misleading, to a certain extent, in the scientific research, technological development, and application of metallic materials, thus keeping metal science in a stage of using experience and repeated tests to amend errors. 


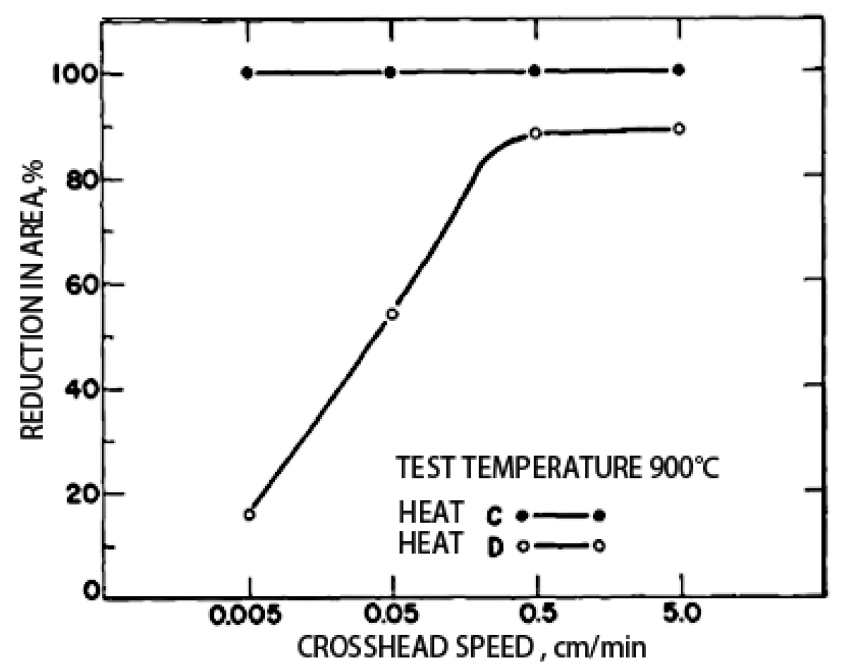

Figure 15. Effect of crosshead speed on the reduction of area at $900{ }^{\circ} \mathrm{C}$ for C-Mn steel heats C and D. Reprinted with permission from ref. [16]. Copyright 1969 Springer Nature.

\section{Paradox of Tensile Test}

A metal or alloy being in a certain condition must correspond to a well determined set of mechanical properties, referred to here as the original mechanical properties. Metals can be divided into two categories: pure metals and trace impurity-containing metals. For the pure metals or alloys, such as $\mathrm{Ni}$ with $0 \mathrm{ppm} \mathrm{S}$, Fe with less than $5 \mathrm{ppm} \mathrm{S}$ (see Figure 12), Al-5Mg alloy with $0.01 \mathrm{ppm}$ Na or less (see Figure 13), and high-purity C-Mn steel (see steel C in Figure 14), the reduction of area does not vary with test temperature. It also does not vary with strain rate for C-Mn steel C, as shown in Figure 15.Accordingly, these metals do not exhibit measurement uncertainty, and the corresponding values in the reduction of area should be their original values. For these pure metals or alloys, the original mechanical property can be determined when tensile-tested at a certain temperature and strain rate.

For metals and alloys containing trace impurities, the reduction of area varies with tensile temperature when the tensile strain rate is constant, as shown in Figures 1 and 3-5 and Figures 12-14. When the tensile temperature is constant, the reduction of area varies with tensile strain rate, as shown in Figures 2 and 6-11 and Figure 15. It is easily understandable that a metal with a certain condition should have a certain reduction of area. However, which one in the several different values induced by the variation of strain rate is its original value? Although the reduction of area determined above is groundlessly considered as the original value of the tested specimen according to the present technology system of tensile testing, it is difficult to prove which one of those testing results is the original reduction of area. The fact of measurement uncertainty indicates instead that the original reduction of area of the tested specimen is not contained in these testing results. However, if the value is not the original property, what property it is? What status of the specimen does it correspond to? All of these are the questions which cannot be answered clearly by the current system of tensile testing. Therefore, data on mechanical properties obtained by the present technology system of tensile testing at a given temperature and strain rate have no definite physical significance.

There is no doubt that a metal possesses a well-determined original mechanical property. Hence, the multiple mechanical properties for a metal obtained by tensile testing at different temperatures and strain rates show that the mechanical property of the specimen has been changed inordinately during the process of tensile testing. The present technology system of tensile testing recognizes that, for a metal specimen, a set of mechanical properties obtained by tensile testing at one set temperature and strain rate is the property of the specimen, and another set of mechanical properties obtained at another set temperature and strain rate is also the property of the specimen. Thus, the current technology system and standard of tensile testing could be in question. 
International Standard ISO 6892-2 has stated that the uncertainty of test results influenced by temperature and strain rate variations must be determined experimentally since these uncertainty values are highly material-dependent. Therefore, it is not currently possible to assign a pre-determined set of temperatures and strain rates for the determination of the original mechanical property of a specimen by tensile testing. It is unwarranted that the present technology system and standard of tensile tests posits that the original mechanical property of the specimen can be determined by testing at a fixed temperature and strain rate $[17,18]$.
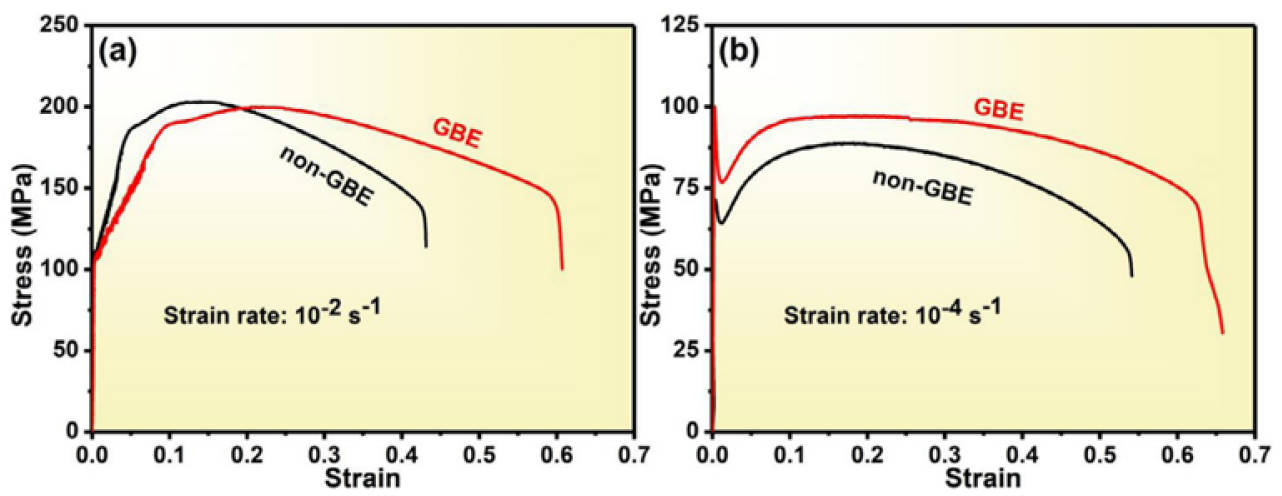

Figure 16. Comparison of tensile properties of non-GBE and GBE Cu-16 at\%Al alloy samples at $723 \mathrm{~K}$ with strain rates: (a) $10^{-2} \mathrm{~s}^{-1}$ and (b) $10^{-4} \mathrm{~s}^{-1}$. Reprinted with permission from ref. [19]. Copyright 2020 Elsevier.

The following situation may occur due to the measurement uncertainty. If there are two alloys, named alloy A and alloy B, the mechanical property of alloy A may be higher than that of alloy B when tested at one strain rate, but the latter may also be higher than the former at another strain rate. Guan et al. [19] reported the testing results exhibited in Figure 16. As shown, when the tensile test is performed at $723 \mathrm{~K}$ with a strain rate of $10^{-2} \mathrm{~s}^{-1}$, the yield strength of non-GBE (grain boundary engineering) $\mathrm{Cu}-16$ at $\% \mathrm{Al}$ alloy is higher that of GBE Cu-16 at\%Al alloy. However, when tested with a strain rate of $10^{-4} \mathrm{~s}^{-1}$, the yield strength of the GBE alloy is higher than that of the non-GBE alloy (see Figure 16). Therefore, the mechanical properties of the two alloys obtained at the same temperature and strain rate cannot compare to each other. Apparently, the above problem is a paradox.

\section{Mechanism of Measurement Uncertainty}

In this section, the microscopic theory of elastic deformation in metals will be elucidated in brief [20-23] and then used to clarify the measurement uncertainty in the reduction of area relative to temperature and strain rate variations, so as to more clearly understand intermediate temperature embrittlement and strain rate embrittlement.

\subsection{Microscopic Theory of Elastic Deformation}

In the 17th century, Robert Hooke, an English physicist, proposed Hooke's law. Since then, the theory of elastic deformation in metals has been restricted to a macroscopic frame that is normalized by Hooke's law. From the start of 21st century Xu has gradually established a microscopic theory of elastic deformation based on Hooke's law [20-23].

\subsubsection{Microscopic Mechanism and Critical Time}

An anelastic deformation will preferentially occur at grain boundaries for the elastic deformation of polycrystalline metals, such as $\mathrm{Ni}, \mathrm{Al}, \mathrm{Cu}, \mathrm{Fe}$, and their alloys, under tension stress at a temperature. Such a micro-mechanism of anelastic deformation in metals was suggested by $\mathrm{Xu}[22,23]$. In this micro-mechanism, vacancies in the matrix can be absorbed into grain boundaries which work as a trap of vacancies under a tension stress. Moreover, the migrating vacancies may drag solute atoms in the form of vacancy-solute complexes 
towards the grain boundaries, to create grain boundary segregation of solutes. At the same time, a concomitant but reverse diffusion of solute atoms away from the boundaries takes place along the established solute concentration gradient. Accordingly, a stress ageing time must exist at which the backward solute diffusion balances the forward complex diffusion, and the solute concentration at the grain boundary reaches a maximum value. This elastic deformation time (EDT) is called the critical time of elastic deformation (ED) at temperature $T\left(t_{\mathrm{c}}(T)\right)$, and is given by

$$
t_{\mathrm{c}}(T)=r^{2} \ln \left(D_{\mathrm{c}}(T) / D_{\mathrm{i}}(T)\right) /\left[\delta\left(D_{\mathrm{c}}(T)-D_{\mathrm{i}}(T)\right]\right.
$$

where $D_{\mathrm{i}}(T)$ and $D_{\mathrm{c}}(T)$ are the diffusion coefficients for solute atoms and complexes in the matrix, respectively, and both are affected by the elastic deformation; $r$ is the mean grain radius; and $\delta$ is a numerical constant, given by $\delta=6 K^{2}$, where $K=r / L, L$ is the mean diffusion length of solute during the critical time.

The critical time of ED has been verified experimentally many times [22-24]. Figure 17 shows that the critical time of ED is about $1 \mathrm{~h}$ at $773 \mathrm{~K}$, at which a maximum of phosphorus concentration appears at the grain boundary under a tensile stress of $30 \mathrm{MPa}$ for a $\mathrm{Cr}$ steel [24]. The critical time of ED for phosphorus segregation in a Cr-Mo low alloy steel was measured by Auger electron spectroscopy to be about $0.5 \mathrm{~h}$ under a tensile stress of $40 \mathrm{MPa}$ at $520{ }^{\circ} \mathrm{C}$ [25]. The critical time of ED at which a maximum grain boundary concentration of sulfur is created is about $3 \mathrm{~h}$ under a tensile stress of $40 \mathrm{MPa}$ at $883 \mathrm{~K}$ for a low alloy steel [26].

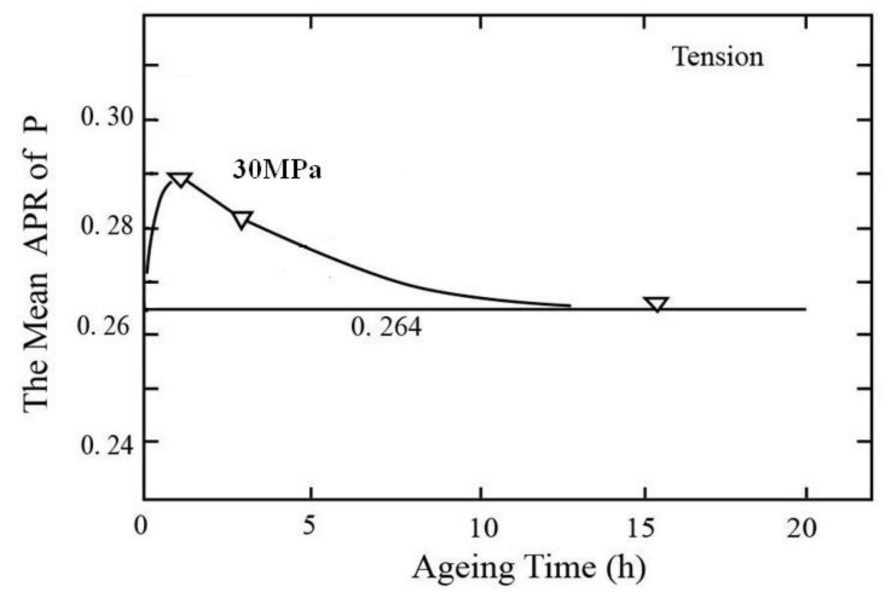

Figure 17. Changes in the mean Auger peak height ratio of phosphorus to iron (APR of $\mathrm{P}$ ) at grain boundaries as a function of ageing time under a tensile stress for a smooth specimen of a $\mathrm{Cr}$ steel. Reprinted with permission from ref. [24]. Copyright 1981 Elsevier.

The grain boundary concentration of the solute during elastic deformation depends on how close the EDT is to the critical time. When the EDT is shorter than the critical time, the segregation concentration decreases with shortening EDT. When the EDT is longer than the critical time, the segregation concentration increases with shortening EDT. Only when the EDT is equal to the critical time does the segregation concentration reach a maximum value as shown in Figure 17 [22,27].

It is difficult to calculate the kinetic plot with Equation (1) because of the lack of data in the presence of elastic deformation. Figure 18 shows a schematic diagram of the relationship between critical time and deformation temperature simulated with Equation (1) for phosphorus in steel, indicating that the critical time always increases with the decrease in deformation temperature. As the deformation temperature is decreased, the diffusivities of both solute atoms and complexes also decrease. Hence a prolonged ageing time is needed to balance the backward diffusion flow of solute atoms with the forward diffusion flow of complexes. As a result, the critical time increases with decreasing deformation temperature. This is a characteristic of the critical time of ED as shown in Figure 18 [22,27]. 


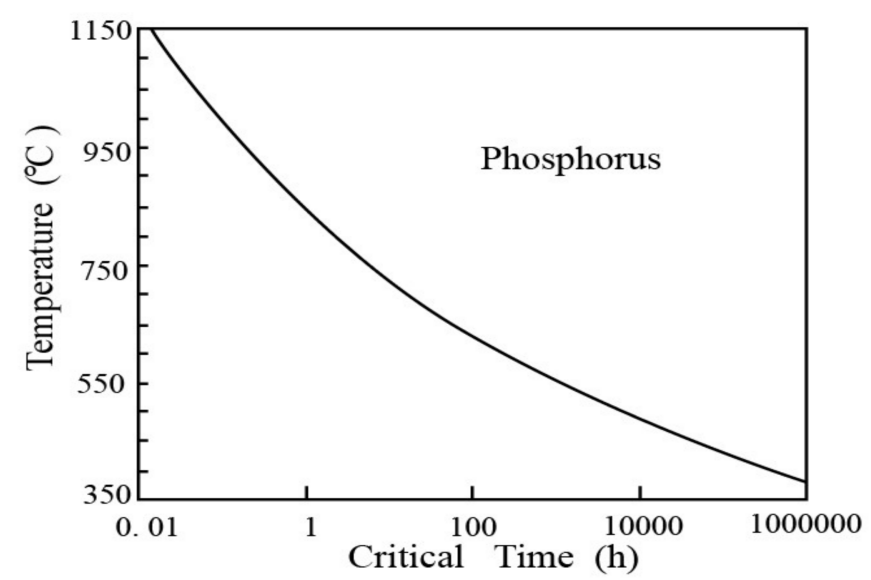

Figure 18. A schematic diagram showing the relationship between critical time and deformation temperature, simulated with Equation (1) for phosphorus in steel. Reprinted with permission from ref. [27]. Copyright 2004 Elsevier.

\subsubsection{Peak Temperature of Segregation and Its Variation}

An anelastic deformation can preferentially occur at grain boundaries for the elastic deformation of a polycrystalline metal under a tensile stress. A maximum concentration of solute under stress equilibrium in the grain boundary region $\left(C_{b(\sigma=\sigma)}\right)$ is given by [22,27]

$$
C_{\mathrm{b}(\sigma=\sigma)}=C_{\mathrm{b}(\sigma=0)}+\left(K_{0} / 2\right) \sigma^{2} / E_{\mathrm{gb}} F_{\mathrm{v}}
$$

where $C_{\mathrm{b}(\sigma=0)}$ is the equilibrium concentration of solute at grain boundaries in the absence of stress, $\sigma$ is the tensile stress, $E_{\mathrm{gb}}$ is the elastic or Young's modulus of grain boundary, $F_{\mathrm{V}}$ is the formation energy of vacancy in the boundary region, and $K_{0}$ is a geometric factor.

Based on Equations (1) and (2), Xu [22,27] formulated the kinetic equations to describe the solute concentration at grain boundary, varying with EDT. For the segregation phase, i.e., the EDT is shorter than the critical time, the kinetic equation is

$$
\begin{aligned}
& {\left[C_{\mathrm{b}}(t)-C_{\mathrm{b}(\sigma=0)}\right] /\left[C_{\mathrm{b}(\sigma=\sigma)}-C_{\mathrm{b}(\sigma=0)}\right]} \\
& =1-\exp \left(4 D_{\mathrm{c}} t / \alpha^{2} d^{2}\right) \operatorname{erfc}\left[2\left(D_{\mathrm{c}} t\right)^{1 / 2} / \alpha d\right]
\end{aligned}
$$

For the desegregation phase, i.e., when the EDT is longer than the critical time, the kinetic equation is

$$
\begin{aligned}
& {\left[C_{\mathrm{b}}(t)-C_{\mathrm{g}}\right] /\left[C_{\mathrm{b}}\left(t_{\mathrm{c}}\right)-C_{\mathrm{g}}\right]} \\
& \quad=(1 / 2)\left\{\operatorname{erf}\left[(d / 2) /\left[4 D_{\mathrm{i}}\left(t-t_{\mathrm{c}}\right)\right]^{1 / 2}\right]-\operatorname{erf}\left[(-d / 2) /\left[4 D_{\mathrm{i}}\left(t-t_{\mathrm{c}}\right)\right]^{1 / 2}\right]\right\}
\end{aligned}
$$

where $C_{\mathrm{g}}$ is the concentration of solute within the grains, $\alpha=C_{\mathrm{b}(\sigma=\sigma)} / C_{\mathrm{g}}, D_{\mathrm{v}}$ and $D_{\mathrm{i}}$ are the diffusion coefficients of complexes and solute atoms in the matrix, respectively, and $d$ is the width of the concentrated layer along the grain boundary.

A schematic diagram obtained from Equations (1)-(4) is shown in Figure 19a. It indicates that the grain boundary concentration of solute varies with EDT at five temperatures. Figure $19 \mathrm{~b}$ is plotted based on Figure 19a, and shows that the grain boundary concentration of solute varies with temperature when the EDT is constant, being $t_{1}$ or $t_{2}\left(t_{1}<t_{2}\right)[7,28]$. 


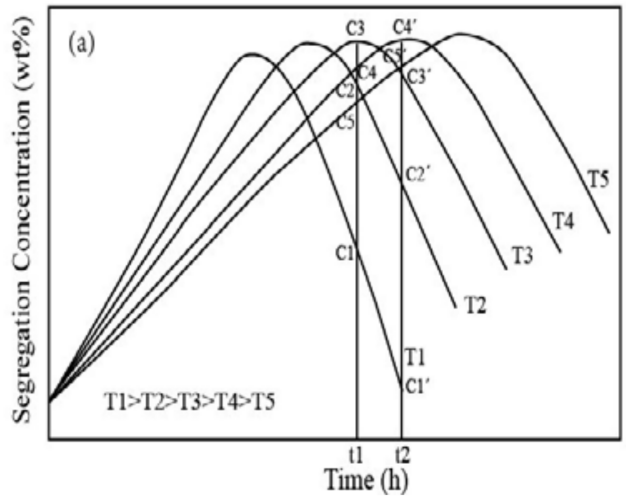

(a)

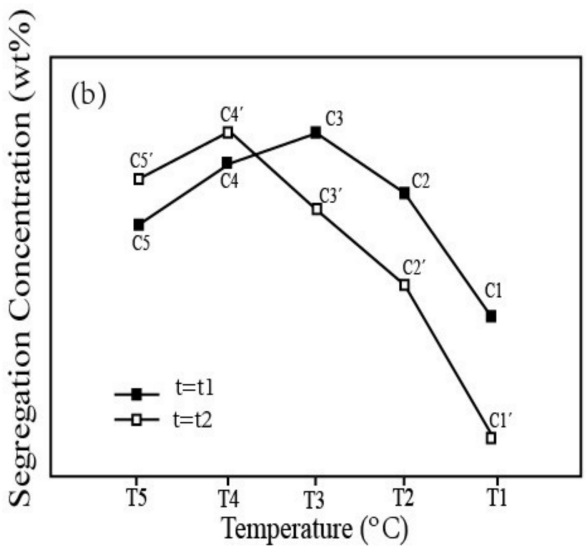

(b)

Figure 19. (a) A schematic diagram showing the variation of grain boundary concentration of solute with elastic deformation time at temperatures $T_{1}, T_{2}, T_{3}, T_{4}$, and $T_{5}\left(T_{1}>T_{2}>T_{3}>T_{4}>T_{5}\right)$. The vertical lines are for the EDTs of $t_{1}$ and $t_{2}$, respectively. (b) Grain boundary concentrations of solute at temperatures $T_{1}, T_{2}, T_{3}, T_{4}$, and $T_{5}$ for the EDTs of $t_{1}$ and $t_{2}$, respectively. Reprinted with permission from ref. [28]. Copyright 2012 Acta Physica Sinica.

It may be summarized from Figure 19 that (1) for an elastic deformation process where the metal is deformed for an identical EDT at different temperatures, there must be a temperature at which the grain boundary segregation of solute reaches a maximum value (peak). The critical time of this temperature is equal or close to the EDT. This temperature is called the peak temperature of segregation induced by elastic deformation; (2) the peak temperature of segregation shifts to lower temperatures when the EDT is prolonged.

In the next section, the measurement uncertainty in the reduction of area relative to test temperature and strain rate will be clarified, based on the variation in grain boundary concentration of solute induced by elastic deformation.

\subsection{Elastic Deformation Induced Measurement Uncertainty}

The procedure of tension testing always includes an elastic deformation stage, an EDT and then sometimes a plastic deformation stage until fracture [1,2]. The amount of elastic deformation a metal can undergo is constant at a certain temperature. Consequently, a certain strain rate in the tension test will correspond to a constant EDT at a test temperature for a metal [23]. Hence the EDT will increase monotonously with the decrease in strain rate. In addition, the critical time of ED will increase monotonously with decreasing deformation temperature. The relationship between the EDT corresponding to the strain rate, and the critical time corresponding to the test temperature, and its change, will be employed to clarify the measurement uncertainty in the reduction of area determined with a tension test system.

\subsubsection{Critical Time Induced Strain Rate Embrittlement}

For the tension test at a fixed temperature with various strain rates, one strain rate must exist at which the corresponding EDT is equal to the critical time at the test temperature, the grain boundary segregation of solute achieves a maximum level, and the reduction of area reaches a minimum value, as described in Section 4.1.1. This strain rate is here termed the critical strain rate (CSR) at the test temperature. For a strain rate which is higher or lower than the CSR, the corresponding EDT will be shorter or longer than the critical time. In this case, the segregation level of the solute will be lower, and the reduction of area will be higher. These are the conditions as shown in Figures 6-8 for Cu-doped Fe-36Ni alloy, S-doped Fe-17Cr and C-Mn steels, respectively. The reduction of area varies with strain rate and there is a strain rate at which the reduction of area reaches a minimum value. This strain rate is the CSR. In Figure 6, the CSR is approximately between $10^{-1} \mathrm{~s}^{-1}$ and $10^{-2} \mathrm{~s}^{-1}$. In Figure 7, it is approximately $1.43 \times 10^{-3} \mathrm{~s}^{-1}$ at $923 \mathrm{~K}$, and $1.43 \times 10^{-4} \mathrm{~s}^{-1}$ at $873 \mathrm{~K}$. In Figure 8, it is approximately between $1 \mathrm{~s}^{-1}$ and $10^{-1} \mathrm{~s}^{-1}$ at $1173 \mathrm{~K}$. 
When the test temperature decreases, the corresponding critical time will increase. A lower strain rate will be required to produce a longer EDT, which is to be equal or close to such a prolonged critical time at the lower test temperature. Hence the CSR, which corresponds to the critical time, will shift to lower strain rates with decreasing test temperature. Just as shown in Figure 7, for Fe-17Cr stainless steel, when the test temperature decreases from $923 \mathrm{~K}$ to $873 \mathrm{~K}$, the CSR also decreases from $1.43 \times 10^{-3} \mathrm{~s}^{-1}$ to $1.43 \times 10^{-4} \mathrm{~s}^{-1}$.

The strain rate adopted in tensile tests cannot always equal the CSR and may be higher or lower than the CSR. For the tensile test where the strain rate adopted at a test temperature is higher than the CSR, the EDT corresponding to the strain rate becomes shorter than the critical time at the test temperature. The EDT decreases and moves away from the critical time with the increase of strain rate. In this case, the grain boundary concentration of solute decreases and the reduction of area or elongation of the tested material increases with increasing strain rate. At the same time, the reduction of area or elongation at a lower test temperature is always higher than that at a higher test temperature due to the CSR decrease, as shown in Figure 7. This phenomenon is also shown in Figures 9 and 10 for C-Mn steel and Fe-40Al-0.6C alloy, respectively. For the C-Mn steel (see Figure 9), the reduction of area increases with increasing strain rate, while the reduction of area at the lower temperature of $1173 \mathrm{~K}$ is always higher than that at the higher temperature of 1273 $\mathrm{K}$, at $1273 \mathrm{~K}$ is higher than at $1323 \mathrm{~K}$, at $1323 \mathrm{~K}$ is higher than at $1342 \mathrm{~K}$, and so on. For the Fe-40Al-0.6C alloy (see Figure 10), the elongation increases with increasing strain rate, and it is higher at $-30^{\circ} \mathrm{C}$ than at room temperature.

For the tensile test where the strain rate adopted at a test temperature is lower than the CSR, the EDT corresponding to the strain rate becomes longer than the critical time at the test temperature. The EDT shortens and moves close to the critical time with increasing strain rate. In this scenario, the grain boundary concentration of solute increases and the reduction of area or elongation of the tested material decreases with increasing strain rate. At the same time, the reduction of area or elongation at a lower test temperature is always lower than that at a higher test temperature due to the CSR decrease (see Figure 7). This characteristic is also shown in Figure 8 for C-Mn steel with S as an impurity. For this steel, the reduction of area decreases with the increase of strain rate, and at the same time the reduction of area at the lower temperature of $1273 \mathrm{~K}$ is always lower than that at the higher temperature of $1423 \mathrm{~K}$.

For an alloy which underwent a given thermal cycle and is then tensile-tested at different temperatures with a certain strain rate, the strain rate may be higher or lower than the CSRs at these test temperatures due to the CSR decrease with decreasing test temperature. As shown in Figures 10 and 11 for Fe-40Al-0.6C alloy, the strain rates adopted at room temperature or $-30{ }^{\circ} \mathrm{C}$ are higher than the corresponding CSR, and thus the elongation increases with the increase in strain rate, as shown in Figure 10. Nevertheless, the strain rates used at $700{ }^{\circ} \mathrm{C}$ are lower than the corresponding CSR and thus the elongation decreases with the increase in strain rate, as shown in Figure 11.

It should be noted that the strain rate embrittlement demonstrated in Figures 6-11 is induced by the segregation of solute or impurity to grain boundaries in various alloy systems. This phenomenon has been verified experimentally in References [3,4,9,11,12]. The segregation of $\mathrm{Cu}$ plays an important role in the strain rate embrittlement as shown in Figures 6 and 9 for Fe-36Ni alloy and 0.1C steel, respectively [9]. The segregation of sulfur and phosphorus causes the strain rate embrittlement as shown in Figure 7 for Fei-17Cr stainless steel [3,4]. It is suggested by Nagasaki et al. [11] that the segregation of sulfur causes fragile grain boundaries, thereby leading to strain rate embrittlement as shown in Figure 8. For the strain rate embrittlement exhibited in Figures 10 and 11 for Fe-40Al-0.6C alloy, it is suggested by Kumar and Pang [12] that the elemental carbon segregation to boundaries may not be effective in discouraging intergranular failure presented by the specimens. 
All experimental observations mentioned above suggest the following statement. For the tension test at a fixed temperature with various strain rates, the EDT increases with the decrease in strain rate. There is always a strain rate whose corresponding EDT is equal to the critical time at the test temperature so as to make the solute grain boundary concentration reach a maximum level and the reduction of area a minimum value. This strain rate is the CSR. The critical time increases with decreasing test temperature so that the CSR becomes lower at a lower test temperature. Such an influence of strain rate on the reduction of area is the measurement uncertainty in the reduction of area relative to strain rate variation in tension tests, termed the strain rate embrittlement.

\subsubsection{Peak Temperature Induced Intermediate Temperature Embrittlement}

For the tension tests at various temperatures with a given strain rate, as depicted in Section 4.1.2, there is always a temperature, the critical time at which is equal to the EDT corresponding to the strain rate. At this temperature, a segregation peak appears, leading to a minimum value in the reduction of area. The critical time becomes longer at a lower temperature, and the EDT becomes longer at a lower strain rate. Accordingly, the temperature corresponding to the segregation peak decreases with lowering strain rate. This is just as shown in Figures 3-5 for Fe-17Cr steel, Al-5\%Mg alloy, and CuNi25 alloy, respectively. For Fe-17Cr steel, there is always a temperature at which the reduction of area has a minimum value. This temperature decreases from $970 \mathrm{~K}$ to $800 \mathrm{~K}$ when the strain rate decreases from $1.43 \times 10^{-1} \mathrm{~s}^{-1}$ to $1.43 \times 10^{-5} \mathrm{~s}^{-1}$ (see Figure 3). For Al-5\%Mg alloy, the temperature corresponding to the minimum reduction of area decreases from $700 \mathrm{~K}$ to $450 \mathrm{~K}$ when the strain rate decreases from $1.02 \times 10^{-1} \mathrm{~s}^{-1}$ to $1.19 \times 10^{-5} \mathrm{~s}^{-1}$ (see Figure 4). For CuNi25 alloy, the temperature corresponding to the minimum reduction of area decreases from $570{ }^{\circ} \mathrm{C}$ to $500^{\circ} \mathrm{C}$ when the strain rate decreases from $2.7 \times 10^{-1} \mathrm{~s}^{-1}$ to $2.7 \times 10^{-3} \mathrm{~s}^{-1}$ (see Figure 5).

It is well known that intermediate temperature embrittlement is intergranular embrittlement induced by impurity segregation to grain boundaries [7]. As confirmed experimentally, the intermediate temperature embrittlement of Fe-17Cr stainless steel is the intergranular embrittlement induced by the segregation of sulfur and phosphorus to grain boundaries [3,4]. The grain boundary segregation of $\mathrm{Na}$ causes intermediate temperature embrittlement of $\mathrm{Al}-5 \% \mathrm{Mg}$ alloy [15]. The embrittlement of $\mathrm{CuNi25}$ alloy is intergranular failure [6]. These all indicate the role of grain boundaries in the ductility of the tested alloys.

Hence, for the tension tests with a strain rate at various temperatures, the critical time of ED is longer at a lower test temperature. There must be a test temperature at which the critical time is equal to the EDT corresponding to the strain rate. At this temperature, the grain boundary segregation reaches a maximum level, and the reduction of area attains a minimum value. When the test temperature is higher or lower than this temperature, the critical time will be shorter or longer than the EDT, and thus the reduction of area will be larger. In such a way, the intermediate temperature embrittlement occurs. That is the measurement uncertainty in the reduction of area relative to test temperature variation in tension tests [7].

The measurement uncertainties in the reduction of area relative to the temperature and strain rate variations in the tension test system, i.e., intermediate temperature embrittlement and strain rate embrittlement, have been clarified above based on the concepts of the grain boundary segregation of solute, the critical time of ED, the EDT, and the CSR as well as their relationship with the test temperature and strain rate.

\section{Measurement Uncertainty of Yield Strength}

The technical standard of metallic tensile testing, ISO, asserts that the yield strength has a measurement uncertainty relative to temperature and strain rate variations. As pointed out in Ref. [29], there are three-dimensional networks of dislocations with expansion area and compression area in metals. Under an elastic tensile stress, the vacancies in the matrix will be absorbed into the regions of three-dimensional networks of dislocations to increase the expansion area. During this process, moving vacancies may combine with solute 
atoms to form their complexes, which will migrate to these regions so as to enable excess solute atoms to segregate there, forming a Cottrell atmosphere, i.e., a non-equilibrium Cottrell atmosphere induced by elastic deformation. The excess solute atoms will diffuse away from the regions because of the established solute concentration gradient. As in the situation of grain boundaries, there is also an elastic deformation time, at which the back diffusion flow of solute atoms balances the forward diffusion flow of complexes, and the solute concentration of the Cottrell atmosphere reaches a maximum value, just as shown in Figure 17, termed the critical time of Cottrell atmosphere $\left(t_{\mathrm{cc}}(T)\right)$, and formulated as [29]

$$
t_{\mathrm{cc}}(T)=L^{2} \ln \left(D_{\mathrm{c}} / D_{\mathrm{i}}\right) /\left[6\left(D_{\mathrm{c}}-D_{\mathrm{i}}\right)\right]
$$

where $L$ is the mean diffusion distance during the critical time at temperature $T$. The solute concentration of the Cottrell atmosphere is related to the degree that the EDT approaches the critical time. The closer to the critical time the EDT, the higher the solute concentration of the Cottrell atmosphere. As shown in Equation (5), the critical time of atmosphere increases with the decrease in the temperature of elastic deformation.

The solute concentration of the Cottrell atmosphere induced by elastic deformation may have the following characteristics [7]:

(1) For an elastic deformation process where the metal is deformed for an identical time at different temperatures, one temperature must exist at which the segregation concentration of the solute at the atmosphere has a maximum (peak) value. The critical time at this temperature is equal or close to the EDT. This temperature is called the peak temperature of atmosphere induced by elastic deformation.

(2) The peak temperature of atmosphere shifts to lower temperatures when the EDT is prolonged at various temperatures.

As found by Cadel et al. [30] in an Fe-40 at\%Al alloy doped with 400 at.ppm B through atomic-scale observations and three-dimensional analyses of Cottrell atmosphere with the aid of three-dimensional atom-probe field-ion microscopy, B enrichment is detected in the vicinity of an edge dislocation. The enrichment appears as a pipe $5 \mathrm{~nm}$ in diameter, being parallel to the dislocation line. The concentration of $\mathrm{B}$ in the core is $\sim 3$ at $\%$. This kind of segregation could influence the yield strength of an alloy. As is well known, the yield stress of a metal or alloy is such a stress that can overcome the pinning of the atmosphere to move dislocations away from the atmosphere. The higher the solute concentration in the atmosphere is, the larger the stress required to move dislocations away from the atmosphere, and thus the larger the yield stress of the metal. Similar to the situation of grain boundaries, the difference between the EDT corresponding to the strain rate and the critical time of the atmosphere at tensile temperature determines the solute concentration of the atmosphere and therefore the yield stress of the metal.

Based on the above, the characteristics in the measurement uncertainty of yield strength may be as follows.

Since the critical time of the atmosphere increases with the decrease in tensile temperature, when the tensile temperature decreases at a fixed strain rate, the difference between the critical time and the EDT will change to cause variations in both the solute concentration of the atmosphere and the yield strength with tensile temperature. There must be a tensile temperature at which the critical time of the atmosphere is equal or close to the EDT, and at the same time a maximum level in the solute concentration of the atmosphere is achieved. Consequently, a maximum value in yield strength is reached. This has been verified by the following experiments. As demonstrated by Xiao and Baker [31], under a strain rate of $1 \times 10^{-4} \mathrm{~s}^{-1}$, the yield strength of Fe-40Al alloy varies with temperature and attains a maximum value at about $675 \mathrm{~K}$ (see Figure 20). 


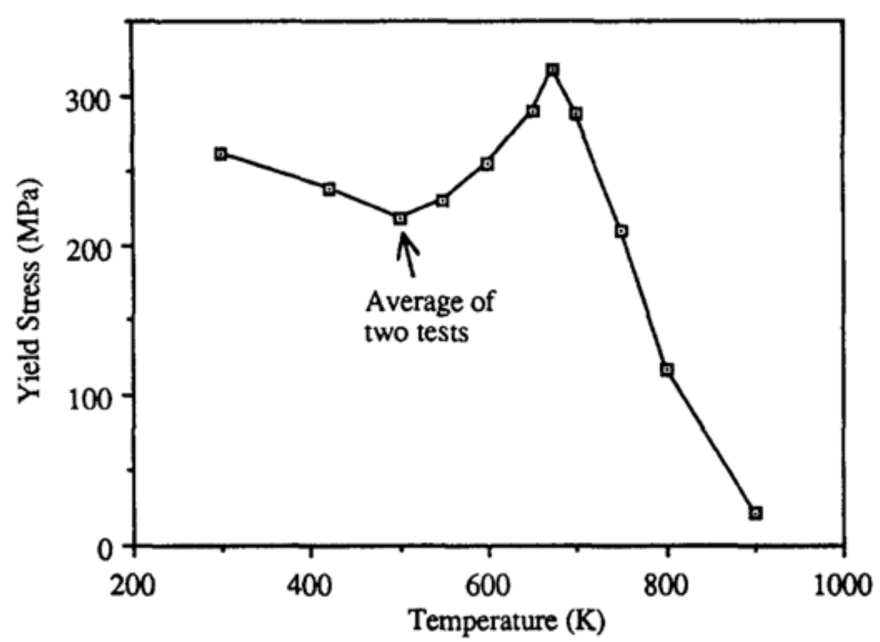

Figure 20. Variation of yield strength with temperature for $\mathrm{Fe}-40 \mathrm{Al}$ alloy, determined under a strain rate of $1 \times 10^{-4} \mathrm{~s}^{-1}$. Reprinted with permission from ref. [31]. Copyright 1993 Elsevier.

Klein and Baker [32] tensile-tested the annealed Fe-45Al alloy samples undoped and doped with $500 \mathrm{ppm}$ boron under a strain rate of $1 \times 10^{-4} \mathrm{~s}^{-1}$ in order to study the variation in yield strength with temperature. Their results indicate that the yield strength changes with tensile temperature for both types of samples, and has a maximum value at $675 \mathrm{~K}$ and $800 \mathrm{~K}$, respectively. Kumar et al. [12] verified experimentally that the Fe-40Al-0.6C alloy could exhibit a maximum yield strength at $600{ }^{\circ} \mathrm{C}$ when testing with a strain rate of $4.7 \times 10^{-4} \mathrm{~s}^{-1}$ at different temperatures (see Figure 21).

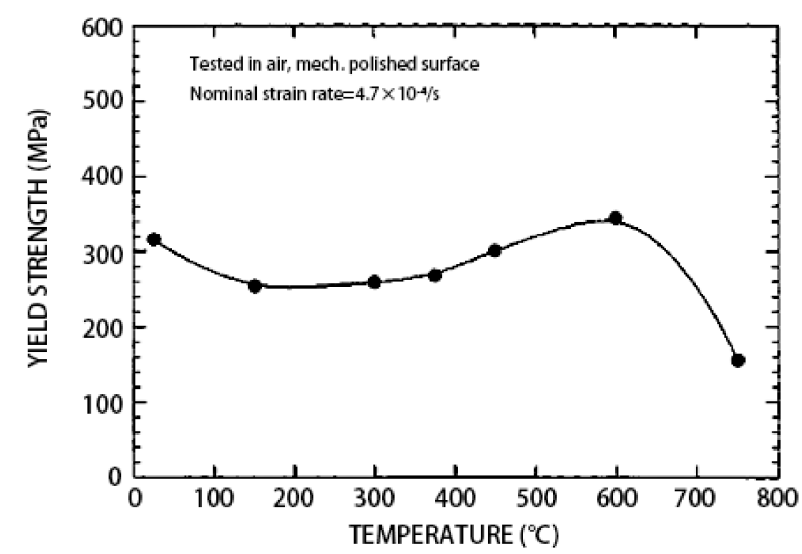

Figure 21. Variation in yield strength with temperature for Fe-40Al-0.6C alloy, determined under a strain rate of $4.7 \times 10^{-4} \mathrm{~s}^{-1}$. Reprinted with permission from ref. [12]. Copyright 1998 Elsevier.

When the strain rate decreases at a constant tensile temperature, the EDT corresponding to the strain rate will increase, thereby resulting in changes in the EDT-critical time difference and the solute concentration of the atmosphere. This will induce a variation in yield strength. A strain rate must exist at which the corresponding EDT is equal or close to the critical time at the test temperature. At this strain rate, both the solute concentration of atmosphere and the yield strength of the tested metal reach maximum.

Wu and Baker [33] tensile-tested the annealed and pre-deformed Fe-40Al and Fe-40Al-1Y single crystal alloys at room temperature with different strain rates. The single crystal alloy was first annealed at $1423 \mathrm{~K}$ for $10 \mathrm{~h}$, cooled slowly in a furnace, and then annealed at $673 \mathrm{~K}$ for 5 days in order to remove remnant vacancies. The pre-deformation was made by a compress force at room temperature to $5 \%$ plastic deformation. Their experimental results are shown in Table 2 and Figure 22. For the pre-deformed Fe-40Al and Fe-40Al-1Y single crystal alloys, not only does the yield strength vary with the tensile strain rate, but 
a maximum yield strength also appears at a strain rate of $1 \times 10^{-2} \mathrm{~s}^{-1}$. The maximum yield strength of Fe-40Al alloy is $380 \mathrm{MPa}$, which is much higher than those determined by higher or lower strain rates. The maximum yield strength of Fe-40Al-1Y alloy is $510 \mathrm{MPa}$, which is also much higher than those determined by higher or lower strain rates. For the annealed single crystal alloys, when the $\mathrm{Fe}-40 \mathrm{Al}$ alloy specimen is extended in a vacuum, the maximum yield strength emerges at a strain rate of $1 \times 10^{-5} \mathrm{~s}^{-1}$, being $207 \mathrm{MPa}$, while the maximum value emerges at a strain rate of $1 \times 10^{-1} \mathrm{~s}^{-1}$, being $210 \mathrm{MPa}$, when extended in air (see Table 2 and Figure 22). The maximum yield strength of Fe-40Al-1Y alloy appears at a strain rate of $1 \times 10^{-2} \mathrm{~s}^{-1}$, being $290 \mathrm{MPa}$, when extended in air (see Table 2). Clearly, the maximum yield strength is much higher for the pre-deformed alloys than for the annealed alloys. This may be due to the increase in vacancy concentration in the matrix by pre-deformation so as to increase the interaction of vacancies, impurity atoms and dislocations, leading to an increase in the impurity concentration in the atmosphere, and in turn an increase in yield strength.

Table 2. Tensile properties of Fe-Al single crystals as a function of environment, pre-straining, and strain rate. Adapted from ref. [33].

\begin{tabular}{|c|c|c|c|}
\hline Alloy & As-Annealed/Pre-Strained & Strainrate $\left(\mathrm{s}^{-1}\right)$ & Yieldstrength (MPa) \\
\hline \multirow{6}{*}{$\mathrm{Fe}-40 \mathrm{Al}$} & Vacuum & & \\
\hline & As-annealed & $1 \times 10^{-5}$ & 200 \\
\hline & & $1 \times 10^{-4}$ & 207 \\
\hline & & $1 \times 10^{-3}$ & 205 \\
\hline & & $1 \times 10^{-2}$ & 203 \\
\hline & & Air & \\
\hline \multirow[t]{9}{*}{$\mathrm{Fe}-40 \mathrm{Al}$} & As-annealed & $1 \times 10^{-6}$ & 170 \\
\hline & & $1 \times 10^{-4}$ & 178 \\
\hline & & $1 \times 10^{-3}$ & 195 \\
\hline & & $1 \times 10^{-2}$ & 205 \\
\hline & & $1 \times 10^{-1}$ & 210 \\
\hline & & 1 & 206 \\
\hline & Pre-strained & $1 \times 10^{-4}$ & 258 \\
\hline & & $1 \times 10^{-2}$ & 380 \\
\hline & & 1 & 280 \\
\hline \multirow[t]{7}{*}{ Fe-40Ai-1Y } & As-annealed & $1 \times 10^{-6}$ & 230 \\
\hline & & $1 \times 10^{-4}$ & 250 \\
\hline & & $1 \times 10^{-2}$ & 290 \\
\hline & & 1 & 280 \\
\hline & Pre-strained & $1 \times 10^{-6}$ & 250 \\
\hline & & $1 \times 10^{-2}$ & 510 \\
\hline & & 1 & 460 \\
\hline
\end{tabular}

As reported by Kumar and Pang [12], the variations in the reduction of area and yield strength with strain rate are shown in Figures 11 and 23 for a polycrystalline Fe-40Al-0.6C alloy tested at $700{ }^{\circ} \mathrm{C}$. The reduction of area decreases, and the yield strength increases with increasing strain rate. Until now, there has been no unified theory to explain these experimental phenomena. For the experimental results in Figure 11, it is pointed out in Refs. $[7,17,20]$ that the EDT corresponding to the strain rate is longer than the critical time of the grain boundary at $700{ }^{\circ} \mathrm{C}$. It decreases and approaches this critical time with increasing strain rate, so as to increase the grain boundary concentration of the solute and reduce the elongation. It may be inferred from Figure 23 that the EDT corresponding to the strain rate is also longer than the critical time of atmosphere at $700{ }^{\circ} \mathrm{C}$. It decreases and approaches this critical time with increasing strain rate, so as to increase the solute concentration of the atmosphere near dislocations and raise the yield strength [20]. 


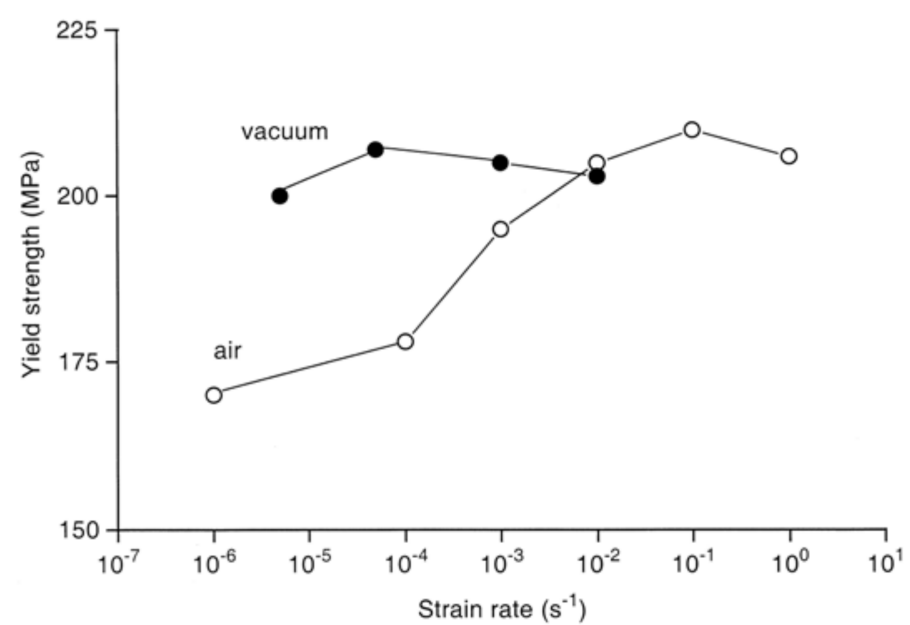

Figure 22. Yield strength versus strain rate for as-annealed Fe-40Al single crystal alloy tested in either air or a vacuum. Reprinted with permission from ref. [33]. Copyright 2001 Elsevier.

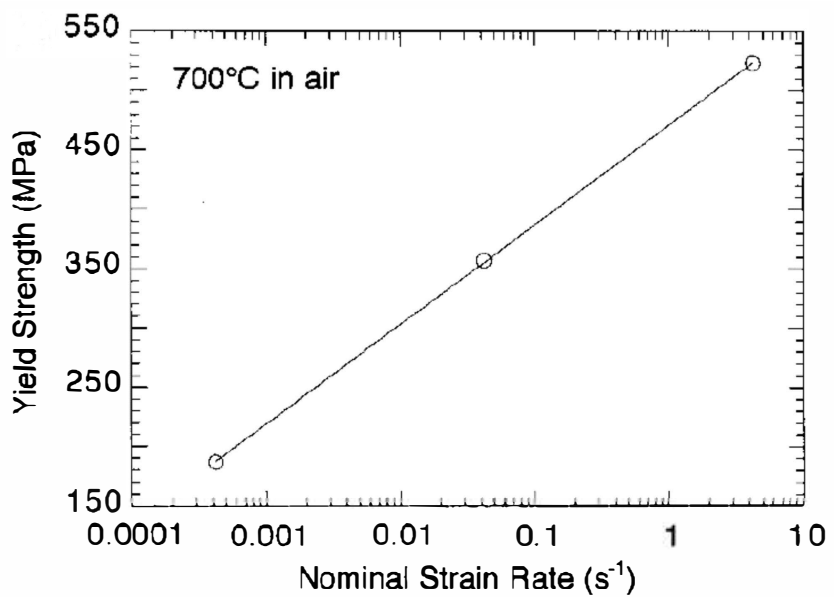

Figure 23. Variation in yield strength with strain rates for Fe-40Al-0.6C alloy. Reprinted with permission from ref. [12]. Copyright 1998 Elsevier.

The measurement uncertainty in the yield strength of metals is induced by the interaction of vacancies, solute atoms and dislocations during the elastic deformation stage of tensile testing. It may be speculated that there is no measurement uncertainty of yield strength if there is no impurity in metals or the amount of impurity is very low. Wu and Baker [33] have experimentally shown that a $6061 \mathrm{Al}$ alloy has no measurement uncertainty of yield strength when tensile tested at room temperature in the strain rate range of $1 \times 10^{-6} \mathrm{~s}^{-1}$ to $1 \mathrm{~s}^{-1}$. The yield strength does not change with variation in strain rate, as shown in Figure 24, and therefore the original yield strength of this alloy can be obtained by this measurement. 


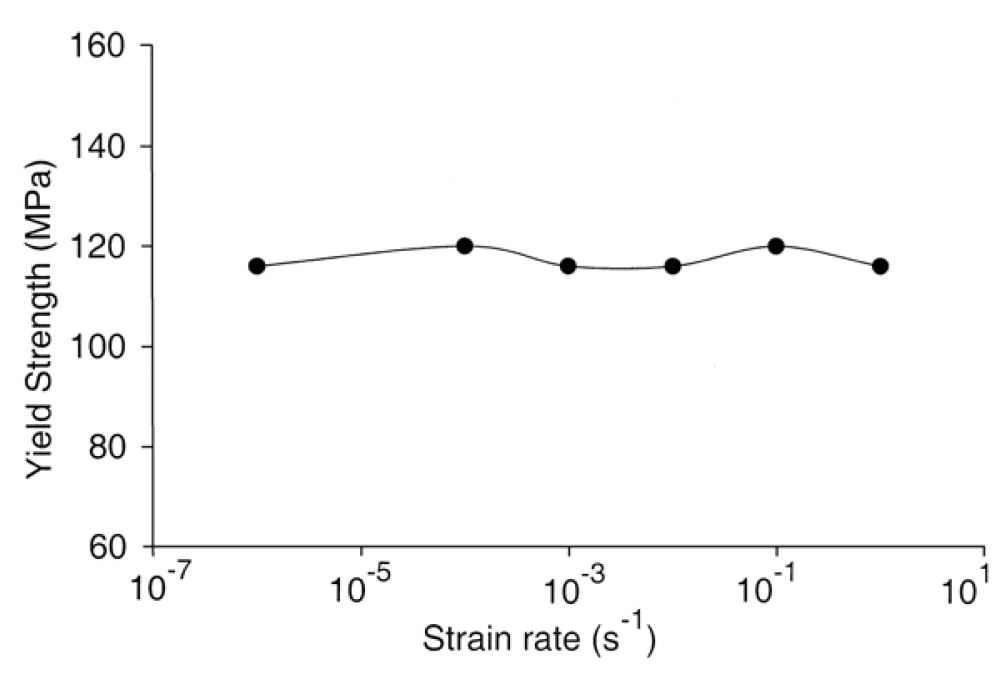

Figure 24. Variation in yield strength with strain rate for $6061 \mathrm{Al}$ alloy in air at room temperature. Reprinted with permission from ref. [33]. Copyright 2001 Elsevier.

\section{A New Technology System of Tensile Testing}

It is seen from the analysis above that a new technology system for tensile testing of metals should be developed. Such a new system has already been suggested based on the mechanism of measurement uncertainty and the micro-theory of elastic deformation in metals $[29,34,35]$.

\section{1. "Mechanical Property-Tensile Strain Rate" Curve}

The above analysis shows that the measurement uncertainty of mechanical properties in tensile tests is a characteristic of the mechanical properties of metals containing trace impurity atoms. At a given temperature, the mechanical properties of metals display a regular variation with strain rate, which can be characterized by the "mechanical propertytensile strain rate" curve at a given temperature.

The elastic deformation of metals under a tensile stress is the most common service condition of metals. Hence, the "mechanical property-tensile strain rate" curve of metals also reveals the variation in mechanical properties with service time when the metals serve under the action of tensile stress at the test temperature. Here, the service time can be characterized by the EDT corresponding to the strain rate. Figure 6 shows the "reduction of area-tensile strain rate" curve of the Cu-containing Fe-36Ni alloy when the alloy serves under the action of tensile stress at the test temperature $1373 \mathrm{~K}$. This figure reflects the variation in the reduction of area with both strain rate and service time (EDT) corresponding to the strain rate. Figure 22 shows the "yield strength-tensile strain rate" curves of Fe-40Al single crystal alloy serving under the action of tensile stress at room temperature in air and in vacuum, respectively. This figure characterizes the variation of yield strength with both strain rate and service time (EDT).

Based on the above analysis, it can be stated that, for the vast majority of metals containing trace impurities, the original mechanical properties are not equivalent to the service mechanical properties, and that the original mechanical properties and service mechanical properties are not equivalent to the mechanical properties during the processing deformation. Therefore, the new technical system for metal mechanics and the tensile test system should include three kinds of mechanical properties: the original mechanical properties, the service mechanical properties, and the mechanical properties during the processing deformation.

\subsection{Original Mechanical Properties}

The original mechanical properties refer to the mechanical properties of the tested metals possessed before tensile tests. The test temperature is generally determined as 
the final temperature of metallurgy and heat treatment processes. Then, different tensile strain rates are selected to measure the "mechanical property-tensile strain rate" curves, as shown in Figures 6 and 22. The original mechanical properties can be determined according to these curves. As mentioned above, the mechanical properties of pure metals do not change with strain rate, and thus the measured mechanical properties are the original ones, as shown in Figure 15 for steel $\mathrm{C}$ and Figure 24 for $6061 \mathrm{Al}$ alloy. If the mechanical properties vary with strain rate, the original ones can be determined from the "mechanical property-tensile strain rate" curves according to the following principles: the higher the strain rate is, the shorter the corresponding EDT, and thus the closer to the original mechanical properties of metals. As shown in Figure 15, for steel D, the reduction of area corresponding to the crosshead speed of $5.0 \mathrm{~cm} / \mathrm{min}$ on the "reduction of area-tensile strain rate" curve is around $82-84 \%$, which is the closest to its original reduction of area. As shown in Figure 6, the reduction of area for the $\mathrm{Cu}$-containing Fe-36Ni alloy is $90-100 \%$ at $1373 \mathrm{~K}$ under the strain rate of $10^{1} \mathrm{~s}^{-1}$, which is the closest to the original reduction of area. If a more accurate original reduction of area is required, it is necessary to further increase the strain rate in the tests.

\subsection{Service Mechanical Properties}

The service mechanical properties of metals can be evaluated as follows. The test temperature is selected according to the service temperature of a metal, and then different strain rates are employed to measure the "mechanical property-tensile strain rate" curve. According to the elastic deformation mechanism, this curve can reveal the variation in the mechanical properties of the metal with the service time (EDT) under the action of tensile stress. Figure 6 shows the "reduction of area-tensile strain rate" curve of the Cu-doped Fe-36Ni alloy when the alloy serves under the action of tensile stress at $1373 \mathrm{~K}$ [9], which depicts the variation in the reduction of area with the service time (EDT). Under the high strain rate of $10^{1} \mathrm{~s}^{-1}$, the corresponding service time (EDT) is very short and thus the grain boundary concentration of $\mathrm{Cu}$ is extremely low so that the reduction of area is up to $100 \%$, which is close to the original reduction of area of the alloy at the service temperature of $1373 \mathrm{~K}$. With decreasing strain rate, the corresponding EDT is prolonged, and the service time is prolonged accordingly. Consequently, the $\mathrm{Cu}$ concentration at grain boundaries increases, thereby leading to a decrease in the reduction of area. The service time (EDT) corresponding to the strain rate of $10^{-1} \mathrm{~s}^{-1}$ is the closest to the critical time at the service temperature, and hence the $\mathrm{Cu}$ concentration at grain boundaries reaches a maximum value. In this scenario, the reduction of area has the lowest value of about $10 \%$, which characterizes the highest brittleness of this alloy under the action of tensile stress. With further decreasing strain rate, the service time (EDT) becomes longer and longer than the critical time, and the grain boundary concentration of $\mathrm{Cu}$ becomes lower and lower accordingly, so that the reduction of area increases. When the strain rate decreases to $10^{-2} \mathrm{~s}^{-1}$, the corresponding service time (EDT) is long enough to ensure that the $\mathrm{Cu}$ atoms can reach the equilibrium grain boundary concentration at the service temperature. A further decrease in strain rate cannot result in any further decrease in $\mathrm{Cu}$ grain boundary concentration, and thus the reduction of area of the alloy remains unchanged, at a value of about $42 \%$. Since this reduction of area does not vary when the alloy continues to serve, it is the service reduction of area. Therefore, the "mechanical property-tensile strain rate" curve at a certain service temperature can reflect the variation of the mechanical properties of metals with the service time (EDT).

\subsection{Mechanical Properties during Processing Deformation}

The "mechanical property-tensile strain rate" curve can characterize the variation in the mechanical properties with the change in processing deformation rate. The mechanical property expressed by each point on the "mechanical property-tensile strain rate" curve at a given temperature is the mechanical property of the metal when it is processing-deformed under the corresponding strain rate. Therefore, the "mechanical property-tensile strain rate" curves demonstrate that the mechanical properties during processing deformation 
are not invariable, but vary with the change in processing deformation rate. The processing deformation also includes the elastic deformation stage and probably the subsequent plastic deformation stage. Hence, the "mechanical property-tensile strain rate" curve can provide a basis for determining an appropriate processing deformation rate in order to benefit the processing deformation. Figures 11 and 23 show the "mechanical property-tensile strain rate" curve of Fe-40Al-0.6C. At the tensile deformation temperature of $700{ }^{\circ} \mathrm{C}$, if the deformation rate ranges from $10^{-4} \mathrm{~s}^{-1}$ to $10^{-3} \mathrm{~s}^{-1}$, the elongation is about $40 \%$, while the yield strength is relatively low, being around $150 \mathrm{MPa}$. Obviously, these properties are beneficial to processing deformation, and endow the material with an excellent processing deformation performance. For the same alloy, if the tensile strain rate ranges from $1 \mathrm{~s}^{-1}$ to $10 \mathrm{~s}^{-1}$ at $700{ }^{\circ} \mathrm{C}$, the elongation is almost zero and the yield strength is very high ( $\sim 500 \mathrm{MPa})$. Apparently, in the higher tensile deformation rate range, the alloy is relatively brittle, and the processing deformation of this alloy would be relatively difficult. Thus, the "mechanical property-tensile strain rate" curve at processing deformation temperature can predict the variation of mechanical properties with processing deformation rate at the processing deformation temperature.

The "reduction of area-tensile strain rate" curve in Figure 7 demonstrates that the reduction of area reaches a minimum value or the brittleness reaches a maximum value under medium strain rates. The "yield strength-tensile strain rate" curve in Figure 22 demonstrates that the yield strength reaches a maximum value under medium strain rates. These results suggest that the higher or lower strain rates, which avoid the medium peak rate, can obtain good properties for processing deformation of metals. Higher deformation rates can also bring about good properties for processing deformation. As shown in Figure 6 , under a processing deformation rate of $10^{1} \mathrm{~s}^{-1}$, the reduction of area of the alloy is as high as $100 \%$, which is beneficial to the processing deformation.

The tensile test results obtained at a fixed temperature and strain rate only represent the mechanical properties in processing deformation at this temperature and strain rate, but they do not represent the general mechanical properties of metals.

Consequently, the mechanical properties of metals, including the original mechanical properties, the service mechanical properties, and the mechanical properties during processing deformation, can all be characterized through the "mechanical property-tensile strain rate" curve, although these three kinds of mechanical properties are not identical to each other. The mechanical property on the curve corresponding to a sufficiently high strain rate is close to the original mechanical property of the tested metal. The curve characterizes the variation in the mechanical property of the tested metal with the change in service time (EDT) under the action of tensile stress. The mechanical property characterized by a point on the curve represents the mechanical property of the tested metal during processing deformation under the strain rate corresponding to this point.

\section{Measurement of Original Mechanical Property}

The measurement uncertainty of the testing results influenced by tensile temperature and strain rate variations leads to tensile testing results obtained at a given temperature and strain rate that are not, in general, the original mechanical property of the tested metal $[29,35,36]$. Almost all those who experiment with tensile testing want to find the original mechanical properties, which correspond to the microstate of the specimen before testing. For example, in order to find the effects of the alloying and heating process on the mechanical properties of metals, the original mechanical properties of tested metals must be measured. Moreover, the original mechanical properties must be determined at various temperatures for studying the hot-ductility of steels. As mentioned above, the new technology system of tensile testing shows that the faster the strain rate is, the closer the mechanical property on the "mechanical property-tensile strain rate" curve is to the original mechanical property $[29,34,35]$. On such a principle, it will be discussed below how to obtain the original mechanical property with tensile testing. 
The new technology system of tensile testing also shows that the microstate of tested metals changes during the process of elastic deformation at a temperature and strain rate, leading to a new microstate different from the original one. This means that the concentration of solute changes at grain boundaries and around dislocations due to elastic deformation. Each set of tensile temperature and strain rate corresponds to a certain time of elastic deformation, a certain microstate, and thus a certain set of mechanical properties. Theoretically, a sufficiently high strain rate exists to produce an elastic deformation time short enough to cause little variation in microstate. Such a strain rate can be used to obtain the original mechanical property of tested metals $[29,35,36]$. As reported by Nachtrab and Chou [16], for C-Mn steel C and steel D (see Table 1), their tensile testing results at $900{ }^{\circ} \mathrm{C}$ (see Figure 15) indicate that for steel $C$ with a high purity the reduction of area remains unchanged, being around $100 \%$, when the crosshead speed characterizing the strain rate increases from $0.005 \mathrm{~cm} / \mathrm{min}$ to $5 \mathrm{~cm} / \mathrm{min}$. This implies that there is no measurement uncertainty relative to strain rate variation for steel $\mathrm{C}$ and the original reduction of area can be obtained under these strain rates, being about 100\%. For steel D with some impurity, the reduction of area increases from $20 \%$ to $82 \%$ when the crosshead speed increases from $0.005 \mathrm{~cm} / \mathrm{min}$ to $0.5 \mathrm{~cm} / \mathrm{min}$, showing the measurement uncertainty relative to the variation of strain rate. With further increasing crosshead speed, the reduction of area maintains $\sim 82 \%$, implying that the crosshead speed of $0.5 \mathrm{~cm} / \mathrm{min}$ is high enough to obtain the original reduction of area for steel D, being about $82 \%$ at $900{ }^{\circ} \mathrm{C}$. Nachtrab and Chou's results above experimentally verify that the higher the strain rate is, the closer the mechanical property on the "mechanical property-tensile strain rate" curve is to the original value. There is a strain rate which is high enough to observe the original mechanical property on the curve. Nachtrab and Chou did not recognize these physical significances when they published their work above.

Some researchers felt that the original mechanical property of tested metals could be obtained by a sufficiently high strain rate, although the new system of tensile testing technology had not yet been established at that time. Kobayashi [37] tensile-tested a low manganese mild steel in order to obtain the original mechanical property with the testing results as shown in Figure 25. The samples of steels 3 and 4 were maintained at $1250{ }^{\circ} \mathrm{C}$ for $5 \mathrm{~min}$ and then cooled to $1050{ }^{\circ} \mathrm{C}$ with various cooling rates ranging from 5 to $150{ }^{\circ} \mathrm{C} / \mathrm{s}$. Subsequently, the samples were tensile tested immediately. It is clear that the results in Figure 25 are tenable only when the original mechanical property of steels 3 and 4 , i.e., the property corresponding to the microstate of steels 3 and 4 before testing, is obtained by tensile testing. This means that a sufficiently high strain rate is required in the testing at $1050{ }^{\circ} \mathrm{C}$. Kobayashi used a crosshead speed of $20 \mathrm{~mm} / \mathrm{s}$ during measurement. It may be speculated that such a strain rate is high enough to obtain the original mechanical property. Even so, the astriction of science development at that time prevented Kobayashi from giving scientific verification.

Kizu and Urabe [38] measured the hot ductility of low manganese mild steel specimens doped with different levels of $S$. The specimens were heated at a rate of $5 \mathrm{~K} \mathrm{~s}^{-1}$ to $1573 \mathrm{~K}$ (reheating temperature) and then soaked for $600 \mathrm{~s}$ in a vacuum. Subsequently, the specimens were cooled to different tensile temperatures ranging from 1023 to $1473 \mathrm{~K}$ at a constant cooling rate of $30 \mathrm{~K} \mathrm{~s}^{-1}$ by nitrogen gas. At each tensile temperature, the specimens were held for $300 \mathrm{~s}$ and subsequently tensile deformed until fracture at a strain rate of $22 \mathrm{~s}^{-1}$. Their experimental results are shown in Figure 26, indicating the influence of tensile temperature and $S$ content on the reduction of area (RA). The strain rate of $22 \mathrm{~s}^{-1}$ used should be high enough to obtain the original mechanical property at the tensile temperatures. If Kobayashi, Kizu and Urabe adopted the present tensile test standard, e.g., a strain rate between $10^{-3} \mathrm{~s}^{-1}$ and $10^{-4} \mathrm{~s}^{-1}$ as recommended by GB/T228.1 [39], the experimental results in Figures 25 and 26 could never be obtained. 


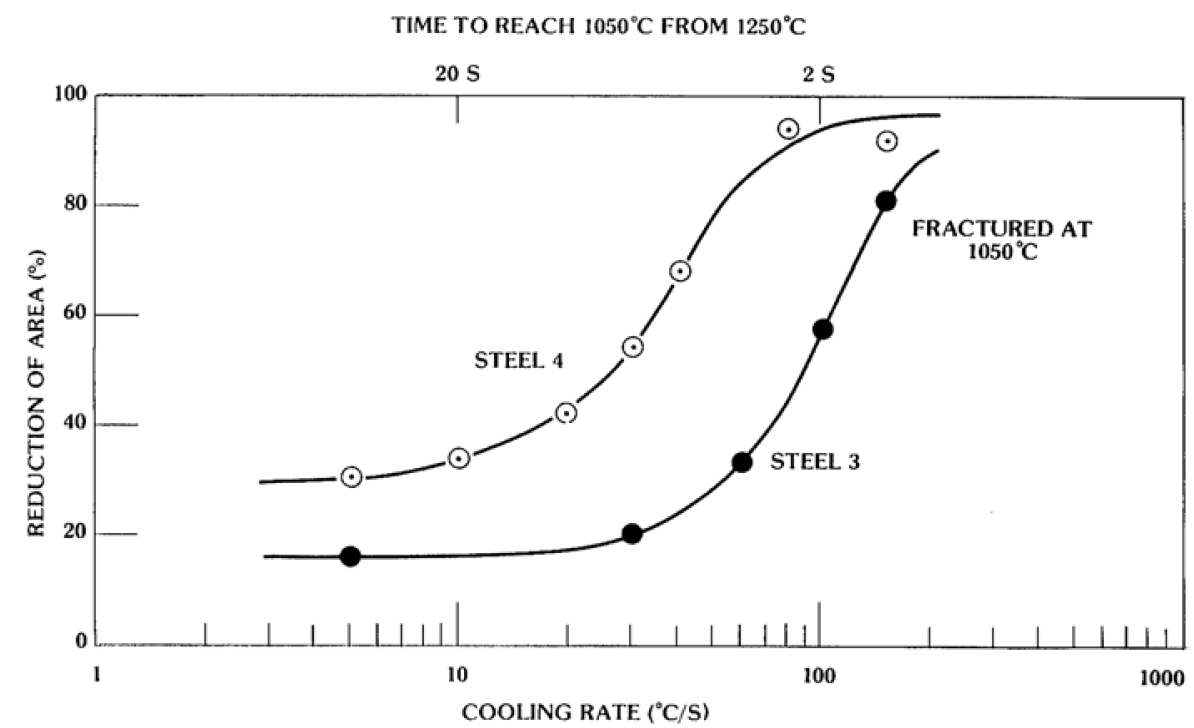

Figure 25. Effect of cooling rate on hot ductility of steels 3 and 4. Reprinted from ref. [37].

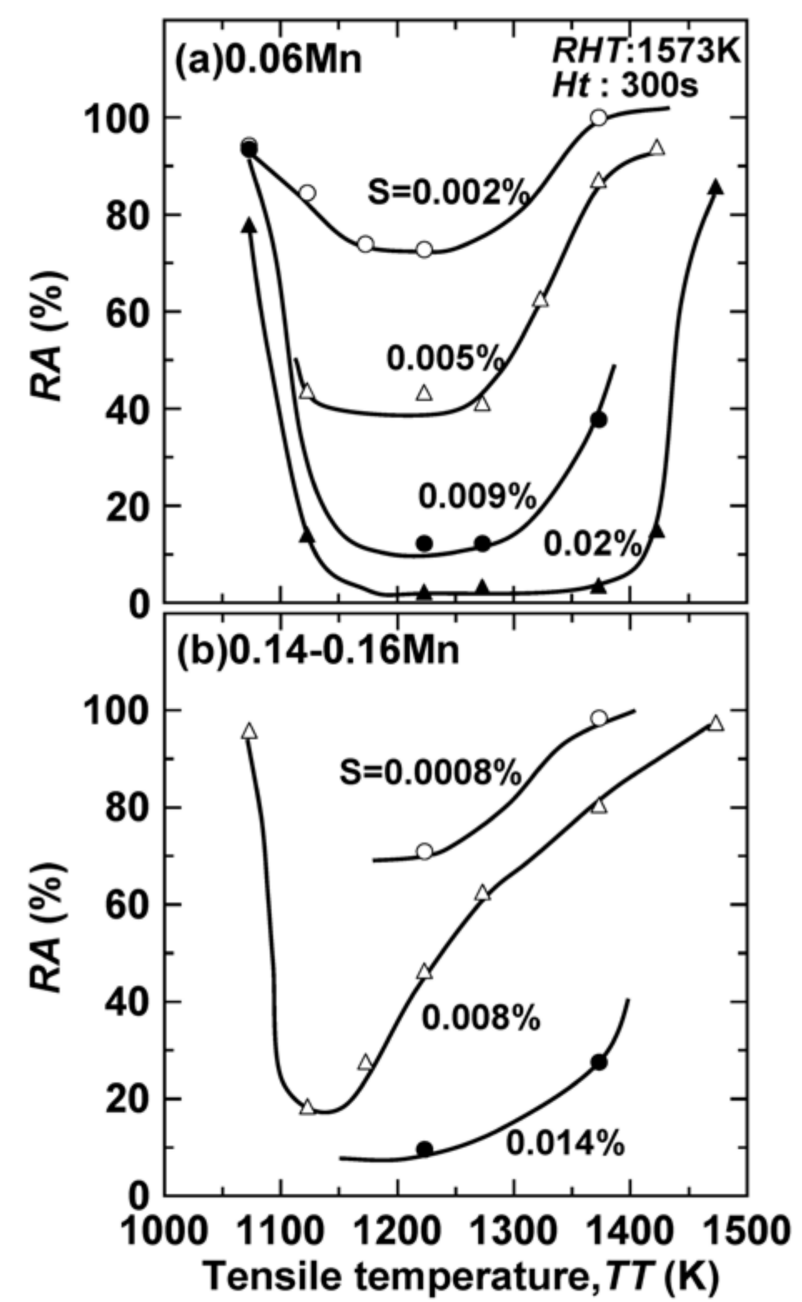

Figure 26. Influence of tensile temperature and $S$ content on the reduction of area (RA) after reheating at $1573 \mathrm{~K}$ for a low manganese mild steel ( $R H T$ = reheating temperature; $H t=$ heating time). Reprinted from ref. [38]. 
Recently, Lin et al. [40] reported the mechanical properties of TA15 titanium alloy prepared by spark plasma sintering (SPS). Figure 27 shows its compression mechanical properties after SPS for $7 \mathrm{~min}$ under $50 \mathrm{MPa}$ at different temperatures (No.3: $900{ }^{\circ} \mathrm{C}$; No.4: $1000{ }^{\circ} \mathrm{C}$; No.5: $1100{ }^{\circ} \mathrm{C}$; and No.6: $1200{ }^{\circ} \mathrm{C}$ ), determined at (a) room temperature and (b) $500^{\circ} \mathrm{C}$, respectively. All the compression tests were performed with a strain rate of $0.01 \mathrm{~s}^{-1}$. The paper did not mention the reason for the choice of strain rate. At room temperature and $500{ }^{\circ} \mathrm{C}$, whether the strain rate of $0.01 \mathrm{~s}^{-1}$ can be used to measure the original mechanical property of the specimen needs further experimental verification. For instance, if a higher strain rate, e.g., $0.1 \mathrm{~s}^{-1}$, is used to gain a mechanical property at $500{ }^{\circ} \mathrm{C}$, and the property is the same as that obtained under the strain rate of $0.01 \mathrm{~s}^{-1}$, the original mechanical property can be measured with the strain rate of $0.01 \mathrm{~s}^{-1}$. Otherwise, the mechanical property obtained with this strain rate is not the original one possessed before testing.
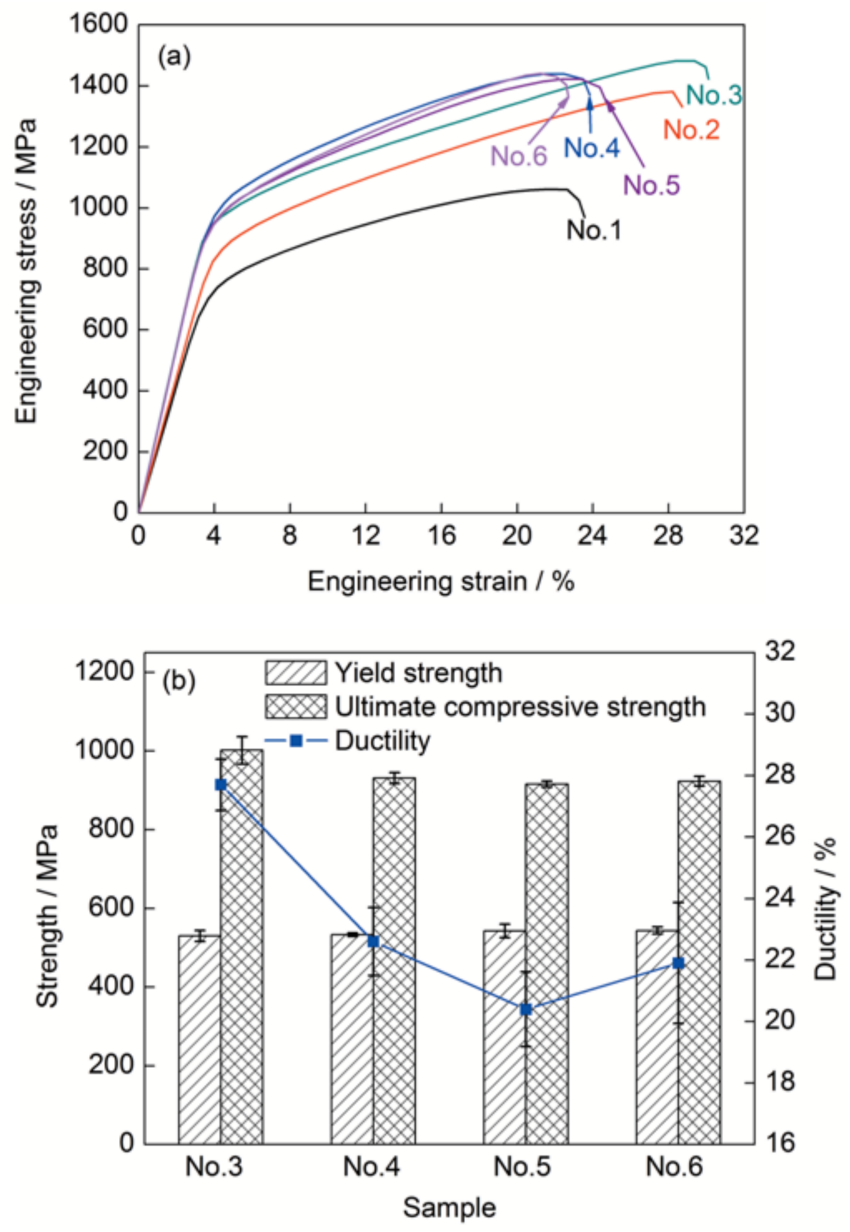

Figure 27. Compression mechanical properties of TA15 titanium alloys prepared by spark plasma sintering at different temperatures (No.3: $900{ }^{\circ} \mathrm{C}$; No.4: $1000{ }^{\circ} \mathrm{C}$; No.5: $1100{ }^{\circ} \mathrm{C}$; and No.6: $1200{ }^{\circ} \mathrm{C}$ ), measured at (a) room temperature and (b) $500^{\circ} \mathrm{C}$. Reprinted with permission from ref. [40]. Copyright 2021 Acta Metallurgica Sinica.

The reduction of area is used as an example of mechanical property in this section. As discussed in Refs. [29,34,35], the solute concentration in Cottrell atmosphere of dislocations changes under the action of elastic stress in tensile testing, leading to a variation in yield strength so as to induce the measurement uncertainty of yield strength. On the "yield strength-tensile strain rate" curve at a given temperature, the higher the tensile strain rate is, the closer the yield strength on the curve to the original yield strength. Therefore, the method of obtaining the original mechanical property mentioned in this section is also applicable for the measurement of the original yield strength of metals. 
The new technology system of tensile testing established in Refs. $[29,34,35]$ shows that each set of tensile temperature and strain rate induces a new microstate and thus a new set of mechanical properties for metals with trace impurities. Hence, the variation in tensile strain rate is very important in the "mechanical property-tensile strain rate" curve. According to the present tensile testing standard, the tensile testing results are determined at a certain strain rate, but the conclusion about the tensile testing results is always not associated with strain rate. Many publications do not label the tensile strain rate used in the tensile testing. It has been shown above that the strain rate is very important because each strain rate corresponds to an EDT, a microstate, and a set of mechanical properties. It may be anticipated that there must be a strain rate in tensile testing which is high enough to produce too short an EDT to change the microstate of the specimen. At that strain rate, the original mechanical property may be determined, as shown in Figure 15. The strain rate corresponding to the original mechanical property is different for different materials as the measurement uncertainty is highly material-dependent. The method of determining the original mechanical property could be used to establish a technology standard for the measurement of original mechanical properties of metals. The original mechanical properties of metals need to be determined so as to investigate the effects of alloying, heat treatment, etc., on the mechanical properties of the metals.

In summary, the faster the tensile strain rate is, the closer the property on the "mechanical property-tensile strain rate" curve is to the original mechanical property. Accordingly, there must be a strain rate which is sufficiently high to determine the original mechanical property of the tested metal on the "mechanical property-tensile strain rate" curve. To determine this strain rate, the testing results need to be determined under various strain rates. If from a certain strain rate the testing results remain unchanged with further increasing strain rate, the strain rate for the determination of the original mechanical property has been found.

Numerous mechanical tests have demonstrated that the present extensometers (mechanical extensometer, electronic extensometer, and optical extensometer) are well able to measure the extension (or strain) in the tensile test of metallic materials. It is worth mentioning that there have been some new stress-monitoring methods being developed, such as mechanical Barkhausen noise (MeBN) [41], magnetic permeability (MP) [42], metal magnetic memory (MMM) [43], and eddy current sensors [44]. MeBN is a mechanical analogue of magnetic Barkhausen noise (MBN) and it is due to jumps of non 180 deg domain walls when the specimen is mechanically loaded. The MeBN technique has been applied to determine the elastic limit of steel and to monitor fatigue tests. It also provides some information on the internal stress distribution [41]. Magnetization involves the nucleation and the motion of magnetic walls and is strongly related to the changes in microstructure, grain size, stress state and deformation in steels. The MP method is based on the sensitivity of the magnetic properties to the material's stress state. It has been used to determine the residual stresses in ferromagnetic steels [42]. The MMM technique has caused a strong reaction in the non-destructive testing (NDT) field and has been investigated extensively over recent years. This technique relies on the measurement of self-magnetic flux leakage of ferromagnetic materials and has been used to detect the stress concentration in ferromagnetic components [43]. Eddy current techniques allow high-speed testing under harsh operating conditions where other techniques cannot be used. The eddy current testing permits force and stress measurements and crack detection in a large variety of conductive materials, either ferromagnetic or non-ferromagnetic [44].

It is noteworthy that none of the above stress-monitoring methods have been formally used in the tensile testing of engineering materials. If some can be used in the future, the measurement uncertainty of tensile mechanical properties relative to strain rate and test temperature variations still exists, as it depends on strain rate or test temperature rather than on the stress-monitoring methods which do not alter the microstate of the specimen. Of course, these new stress-monitoring methods will be very useful in engineering practice if they can be formally applied to the tensile or compression mechanical testing of engineering materials. 


\section{Representation of Mechanical Properties for High-Entropy Alloys}

Over the past twenty years, a new alloying concept has been proposed, called highentropy alloys (HEAs). These new materials are formed by combining $n$ elements of roughly equimolar concentrations. When $n$ is equal to or more than 5 , the high entropy of mixing can stabilize solid-solution-like phases with simple crystal structures rather than forming complex intermetallic phases. Although these alloys may be compositionally complex, they are microstructurally simple. Clearly, this concept offers an opportunity to develop fundamentally new classes of alloys for structural applications. Alloying element combinations previously perceived as objectionable due to microstructure instability may now be a possibility, suggesting completely new families of light metal alloys, high strength alloys, and high-temperature alloys. Therefore, the study of HEAs has become a research hotspot in metallic materials worldwide [45-48].

References [29,34-36] give a new technology system of tensile testing: a curve of "mechanical property-tensile strain rate" at a given temperature, characterizing the original mechanical property, the property in service, and the property during processing deformation. This new technology system reveals that the mechanical property determined by tensile testing at a given temperature and strain rate is in general not the original mechanical property of the specimen possessed before the testing. It is unclear what micro-structure is corresponded by these properties and therefore these properties could have no physical meaning [29]. Therefore, the new technology system of tensile testing changes both the basic conception of metallic dynamics and the technology system of testing $[18,29,34]$. In this section, it will be demonstrated that high-entropy alloys also exhibit the measurement uncertainty induced by test temperature and strain rate variations.

\subsection{Experimental Results and Discussion}

8.1.1. Measurement Uncertainty Induced by Temperature Variation

Gludovatz et al. [49] prepared a CrMnFeCoNi alloy with high purity elemental starting materials by arc melting and drop casting into rectangular-cross-section copper molds, followed by cold forging and cross rolling at room temperature into sheets roughly $10 \mathrm{~mm}$ thick. After recrystallization, the alloy had an equiaxed grain structure. Uniaxial tensile specimens in accordance with ASTM standard E1820 (10) were machined from these sheets by electrical discharge machining. The uniaxial stress-strain curves were determined at $293 \mathrm{~K}, 200 \mathrm{~K}$, and $77 \mathrm{~K}$, respectively, as shown in Figure 28. With a decrease in temperature from $293 \mathrm{~K}$ to $77 \mathrm{~K}$, the yield strength and ultimate tensile strength increases by $\sim 85 \%$ and $\sim 70 \%$, being $\sim 760$ and $\sim 1280 \mathrm{MPa}$, respectively. Similarly, the ductility (strain to failure) increases by $\sim 25 \%$, being $\sim 0.7$ [49]. These indicate the measurement uncertainty of the $\mathrm{CrMnFeCoNi}$ alloy induced by the tensile temperature variation at a given strain rate [2,48].

The effect of temperature (296 to $1473 \mathrm{~K}$ ) on the compression mechanical property of a TaNbHfZrTi alloy was studied by Senkov et al. [50]. Figure 29 and Table 3 show the "stress-strain" curves under a strain rate of $10^{-3} \mathrm{~s}^{-1}$, and the variation in yield strength with compression temperature, respectively. The yield strength of the alloy varies with the variation in compression temperature. This is the measurement uncertainty induced by compression temperature variation. 


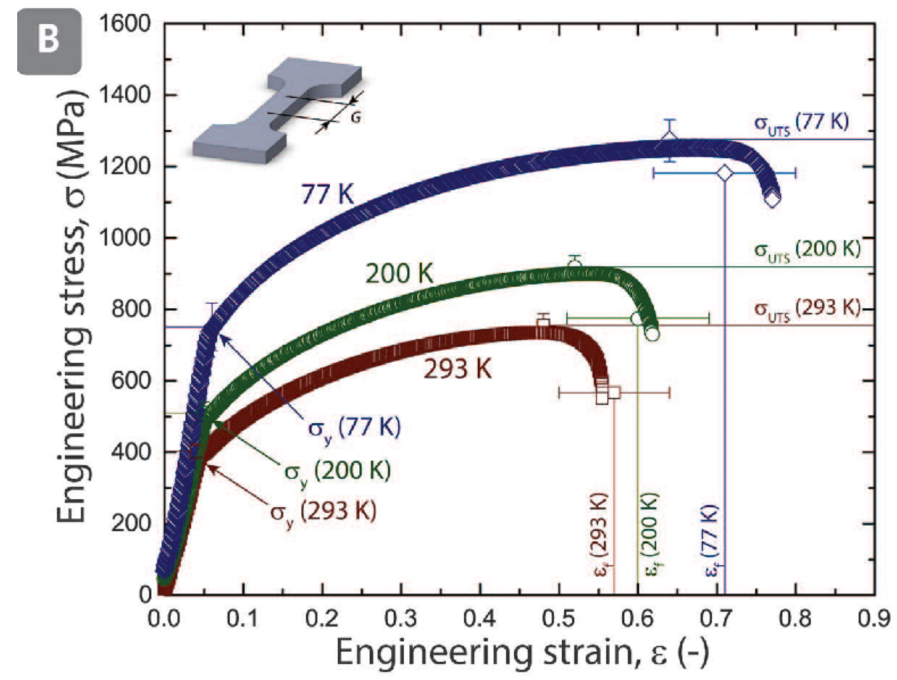

Figure 28. Mechanical properties of a CrMnFeCoNi high entropy alloy: yield strength $\left(\sigma_{\mathrm{y}}\right)$, ultimate tensile strength $\left(\sigma_{U T S}\right)$, and ductility (strain to failure, $\left.\varepsilon_{f}\right)$ at three temperatures 77,200 and 293 K, Reprinted with permission from ref. [49]. Copyright 2014 The American Association for the Advancement of Science.

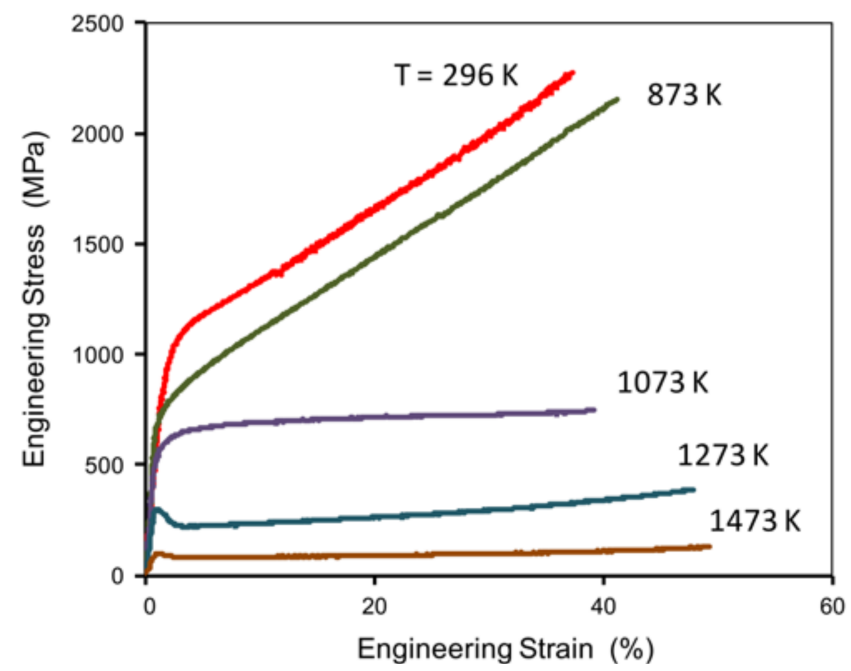

Figure 29. Engineering stress - strain compression curves of TaNbHfZrTi alloy at different temperatures determined with a strain rate of $10^{-3} \mathrm{~s}^{-1}$. Reprinted with permission from ref. [50]. Copyright 2012 Springer Nature.

Table 3. Compression yield strength $\left(\sigma_{0.2}\right)$ of TaNbHfZrTi alloy at different temperatures $(T)$. Adapted from ref. [50].

\begin{tabular}{ccccccc}
\hline $\boldsymbol{T}(\mathbf{K})$ & $\mathbf{2 9 6}$ & $\mathbf{6 7 3}$ & $\mathbf{8 7 3}$ & $\mathbf{1 0 7 3}$ & $\mathbf{1 2 7 3}$ & $\mathbf{1 4 7 3}$ \\
\hline$\sigma_{0.2}(\mathrm{MPa})$ & 929 & 790 & 675 & 535 & 295 & 92 \\
\hline
\end{tabular}

The strain rate: $10^{-3} \mathrm{~s}^{-1}$.

As reported by Senkov et al. [51], a high-entropy Nb25Mo25Ta25W25 alloy is compression tested at temperatures ranging from 600 to $1600{ }^{\circ} \mathrm{C}$, and the yield strength decreases from $561 \mathrm{MPa}$ down to $405 \mathrm{MPa}$, while it decreases from $862 \mathrm{MPa}$ down to $477 \mathrm{MPa}$ for a high-entropy V20Nb20Mo20Ta20W20 alloy. Clearly, these two high-entropy alloys also have the measurement uncertainty of yield strength induced by the variation in test temperature. 
Kraai and Floreen [13] tensile tested high-purity nickel at temperatures ranging from 400 to $800{ }^{\circ} \mathrm{C}$ and obtained a constant reduction of area ( 90\%); Liu et al. [14] tensile tested high-purity iron at temperatures ranging from 700 to $1200{ }^{\circ} \mathrm{C}$ and obtained a constant reduction of area $(\sim 100 \%)$; Nachtrab and Chou [16] tensile tested a high-purity C-Mn steel at temperatures ranging from 600 to $1200{ }^{\circ} \mathrm{C}$ and obtained a constant reduction of area $(\sim 100 \%)$. These experimental results show that high-purity metals have no measurement uncertainty of mechanical properties and only the metals containing impurities have measurement uncertainty induced by the variation in tensile temperature [29]. It is shown that only when the variation in temperature alters the microstate of metals, such as the solute concentration at grain boundaries or dislocations, does the measurement uncertainty emerge [29]. As pointed out in Ref. [52], the present production technique cannot produce high-entropy alloys with a very high purity. Therefore, the variation in mechanical properties with test temperature shown in Figures 28 and 29 should be the measurement uncertainty induced by the interaction of solute atoms and vacancies with grain boundaries/dislocations, thereby changing the mechanical properties. The measurement uncertainty in the mechanical properties of high-entropy alloys should result from such an interaction.

\subsubsection{Measurement Uncertainty Induced by Strain Rate Variation}

Huo et al. [53] tensile-tested a high-entropy CoCrFeNi alloy at room temperature with strain rates of $1 \times 10^{-2} \mathrm{~s}^{-1}, 1 \times 10^{-3} \mathrm{~s}^{-1}$ and $1 \times 10^{-4} \mathrm{~s}^{-1}$ to determine the mechanical properties as shown in Figure 30. It is certain that the specimens of the highentropy CoCrFeNi alloy before testing should correspond to a certain micro-structure with a certain set of corresponding mechanical properties. Micro-structure and macro-property are one-to-one correspondence. However, there are three sets of different strength and toughness values (see Figure 30) corresponding to the three strain rates. Which one in the three sets of values is the original mechanical property of the high-entropy alloy possessed before testing? Or, which one in the three strain rates can be used to measure the original mechanical property of the alloy? It is seen from the above discussion that there is no definite answer, i.e., these problems are not clear according to the current technology system of tensile testing. This could be the problem in metallic mechanics induced by the measurement uncertainty. For the majority of metals containing impurities, the tensile testing results obtained at a given temperature and strain rate with the current technology system of tensile testing, cannot represent the original mechanical property of the metals. Therefore, the testing results could have no specific physical significance.

Senkov et al. [50] also compression tested the high-entropy TaNbHfZrTi alloy at $1073 \mathrm{~K}$ with different strain rates and the results are shown in Figure 31 and Table 4. Obviously, the yield strength varies with strain rate at this fixed temperature. It is $550 \mathrm{MPa}$ at $10^{-1} \mathrm{~s}^{-1}, 535 \mathrm{MPa}$ at $10^{-3} \mathrm{~s}^{-1}$, and $285 \mathrm{MPa}$ at $10^{-5} \mathrm{~s}^{-1}$. Which one of these results is the original yield strength of the alloy at $1073 \mathrm{~K}$ ? It is difficult to answer this question according to the current technology system of tensile testing. Apparently, the measured results in Table 3 could not be effective in terms of those in Table 4 . Which one of the five yield strength values in Table 4 corresponds to the status of the alloy at $1073 \mathrm{~K}$ possessed before deformation? This question is also unclear under the present technology system of tensile testing and therefore the results in Table 4 could not have specific physical significance. 

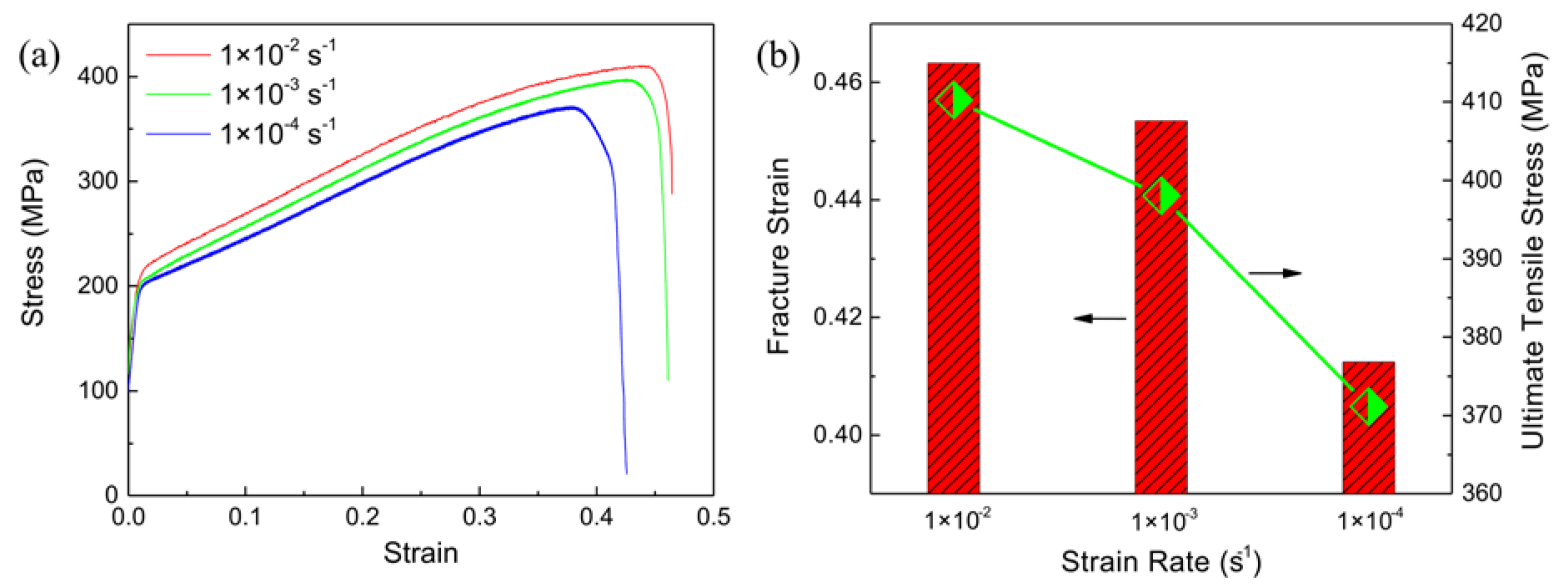

Figure 30. Stress-strain curves and data of a CoCrFeNi high entropy alloy under different strain rates: (a) stress-strain curves and (b) corresponding fracture strain and UTS. Reprinted with permission from ref. [53]. Copyright 2017 Elsevier.

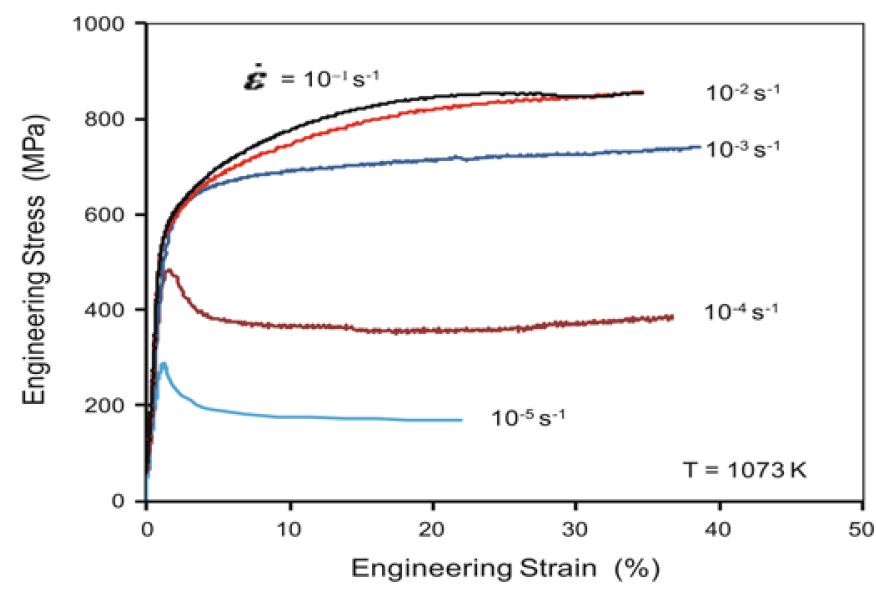

Figure 31. Engineering stress-strain compression curves of TaNbHfZrTi alloy at $1073 \mathrm{~K}$ under different strain rates. Reprinted with permission from ref. [50]. Copyright 2012 Springer Nature.

Table 4. The yield strength $\left(\sigma_{0.2}\right)$ of TaNbHfZrTi alloy determined with different strain rates at 1073 K. Adapted from ref. [50].

\begin{tabular}{cccccc}
\hline Strain Rate $\left(\mathbf{s}^{-\mathbf{1}}\right)$ & $\mathbf{1 0}^{-\mathbf{5}}$ & $\mathbf{1 0}^{-\mathbf{4}}$ & $\mathbf{1 0}^{-\mathbf{3}}$ & $\mathbf{1 0}^{-\mathbf{2}}$ & $\mathbf{1 0}^{-\mathbf{1}}$ \\
\hline$\sigma_{0.2}(\mathrm{MPa})$ & 285 & 475 & 535 & 543 & 550 \\
\hline
\end{tabular}

Nachtrab and Chou [16] tensile tested a high-purity C-Mn steel at room temperature at the strain rate range of 0.005 to $5.0(\mathrm{~cm} / \mathrm{min})$ with a constant reduction of area $(\sim 100 \%)$ obtained. Therefore, there is no measurement uncertainty of yield strength for this high-purity C-Mn steel. Wu and Baker [33] tested a high-purity $6061 \mathrm{Al}$ alloy at room temperature with the strain rate range $10^{-6} \mathrm{~s}^{-1}-10^{1} \mathrm{~s}^{-1}$ with a nearly constant yield strength $(\sim 120 \mathrm{MPa})$ obtained, indicating that there is no measurement uncertainty of yield strength for this high-purity $\mathrm{Al}$ alloy. Therefore, the measurement uncertainty induced by the variation of tensile strain rate should be caused by the interaction of solute atoms and vacancies with dislocations under an elastic stress at different strain rates (different EDTs or interaction times), thereby leading to different solute concentrations at the atmosphere [29]. The measurement uncertainty of yield strength induced by the variation in strain rate for the high-entropy alloy could be a result of this effect. 
As described in ref. [29], if a metal has the measurement uncertainty induced by the variation in test temperature, it also has the measurement uncertainty induced by the variation in strain rate, and vice versa. This means that the metals have the measurement uncertainties induced by both temperature and strain rate variations at the same time, as shown by the experimental results on the above-mentioned high-entropy TaNbHfZrTi alloy [49].

Like traditional alloys, high-entropy alloys have problems in the representation of mechanical properties due to the measurement uncertainty. The experimental result determined at a given temperature and strain rate is not the original mechanical property of the specimen and could have no specific physical significance and comparability [29]. Just as indicated in a report issued recently in the USA [52], the present academic world has not comprehensively understood the effect of impurity on the deformation of high-entropy alloys, the relation between defect and micro-structure evolution, and their effect on the mechanical properties. The researchers and makers of high-entropy alloys have not found a suitable method of eliminating the measurement uncertainty [52].

\subsection{Mechanical Property Characterization}

Recently, it has been indicated in Refs. $[7,17,18,36]$ that the microscopic theory of elastic deformation in metal reveals the measurement uncertainty of mechanical property resulting from the variation of microscopic structure during the elastic deformation stage of tensile testing when the test temperature and strain rate vary. The variation in microscopic structure, changing the solute concentration at grain boundaries and around dislocations and thus the mechanical property, induces the measurement uncertainty. Further, a new technology system of tensile testing is proposed in refs. [29,35], i.e., the curve of "mechanical property-tensile strain rate" at a given temperature is used to represent three kinds of mechanical properties: original mechanical property, service mechanical property, and processing deformation mechanical property [34]. This new technology system is also suitable for the high-entropy alloys.

\subsubsection{Original Mechanical Property}

The process of tensile testing includes the stage of elastic deformation and thereafter the stage of plastic deformation until failure. The value of elastic deformation of a metal is a constant at a given temperature. Hence, the elastic deformation time (EDT) in tensile testing is a constant at a fixed strain rate and decreases with the increase of strain rate $[29,35]$. The higher the strain rate, the shorter the EDT is, and hence the closer the mechanical property on the "mechanical property-tensile strain rate" curve is to the original property [35]. The "yield strength-strain rate" curve for a high-entropy TaNbHfZrTi alloy at $1073 \mathrm{~K}$ as shown in Figure 32 indicates that the yield strength of $550 \mathrm{MPa}$ at the strain rate of $10^{-1} \mathrm{~s}^{-1}$ should be closer to the original mechanical property of the high-entropy alloy at $1073 \mathrm{~K}$ as compared with those at other lower strain rates. The curves of "fracture strain-tensile strain rate" and "ultimate tensile stress-tensile strain rate" are shown in Figure 30 for highentropy $\mathrm{CoCrFeNi}$ alloy at room temperature. The fracture strain 0.46 and ultimate tensile stress $410 \mathrm{MPa}$ at a strain rate of $10^{-2} \mathrm{~s}^{-1}$ should be closer to the original fracture strain and original ultimate tensile stress than those at other two lower strain rates. Therefore, as the strain rate used increases, the mechanical property will be closer and closer to the original value [18,29]. 


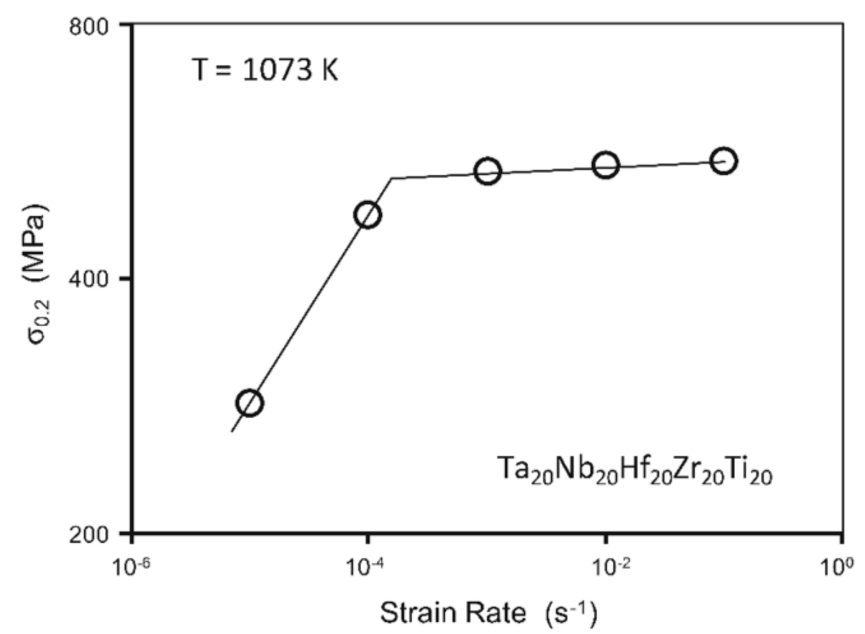

Figure 32. The "yield strength-strain rate" curve of high-entropy TaNbHfZrTi alloy at $1073 \mathrm{~K}$, plotted from the data in Table 4. Reprinted with permission from ref. [50]. Copyright 2012 Springer Nature.

\subsubsection{Service Mechanical Property}

The elastic deformation status under a tensile stress is as the same as the usual service status of the high-entropy alloy. Therefore, the EDT corresponding to the strain rate of testing can be used to characterize the service time. The curve of "mechanical propertystrain rate" at a given temperature can represent the variation of the mechanical property with the service time at the temperature. Figure 32 indicates the variation of yield strength with service time (EDT) at $1073 \mathrm{~K}$ for TaNbHfZrTi alloy. The yield strength in service is $550 \mathrm{MPa}$ when the service time is equal to the EDT for the strain rate of $10^{-1} \mathrm{~s}^{-1}$, while it is $285 \mathrm{MPa}$ when the service time is equal to the EDT for the strain rate of $10^{-5} \mathrm{~s}^{-1}$, decreasing with decreasing strain rate. The curve of "mechanical property-strain rate" in Figure 30 shows that the fracture strain in service decreases from 0.46 to 0.41 and the ultimate tensile stress in service from $410 \mathrm{MPa}$ to $370 \mathrm{MPa}$ when the CoCrFeNi alloy serves from the EDT of strain rate $10^{-2} \mathrm{~s}^{-1}$ to that of strain rate $10^{-4} \mathrm{~s}^{-1}[29,35]$.

\subsubsection{Processing Deformation Mechanical Property}

Each point on the curve of "mechanical property-strain rate" represents the mechanical property of the tested alloy when it is processing deformed with the strain rate corresponding to this point. The yield strength of the TaNbHfZrTi alloy is $535 \mathrm{MPa}$ when it is processing deformed at $1073 \mathrm{~K}$ with a strain rate of $10^{-3} \mathrm{~s}^{-1}$ (see Figure 32). It is clear that the processing deformation property of an alloy varies with strain rate in processing deformation. For instance, the yield strength of the TaNbHfZrTi alloy is $285 \mathrm{MPa}$ when the alloy is processing deformed at a strain rate of $10^{-5} \mathrm{~s}^{-1}$ while it is $550 \mathrm{MPa}$ when processing deformed at a strain rate of $10^{-1} \mathrm{~s}^{-1}$, i.e., the yield strength of the alloy in processing deformation changes with the deforming rate [35] (see Figure 32). Moreover, the fracture strain is 0.41 and ultimate tensile stress is $370 \mathrm{MPa}$ for the $\mathrm{CoCrFeNi}$ alloy when the alloy is processing deformed at room temperature with a strain rate of $10^{-4} \mathrm{~s}^{-1}$, and these values increase to 0.46 and $410 \mathrm{MPa}$, respectively, when it is processing deformed at a strain rate of $10^{-2} \mathrm{~s}^{-1}$ (see Figure 30) $[29,35,36]$.

It has been experimentally verified that, for a traditional alloy, a maximum yield strength frequently emerges at intermediate strain rates on the curve of "yield strengthtensile strain rate", and a minimum reduction of area or elongation on the curve of "reduction of area or elongation-tensile strain rate" [35]. However, there have been no similar experimental results reported in high-entropy alloys. This may be because the database of the testing results is still small for high-entropy alloys. On the other hand, the arrangement of atoms in high-entropy alloys is in much more disorder than that in traditional alloys due to the unique atomic structure and serious lattice distortion, so that the equilibrium concentration of vacancies in the high-entropy alloys could be much higher than that in the traditional 
alloys. If the high-entropy alloy includes sufficient impurity atoms, the vacancies would combine with impurity atoms to form some quantity of complexes, and these complexes would diffuse to grain boundaries/dislocations under an elastic stress. In this case, it would be easier to induce the measurement uncertainty of testing results in the high-entropy alloys than the traditional alloys. These need further experimental verification.

\section{Summary}

The measurement uncertainty of tensile testing results influenced by test temperature and strain rate variations is a widespread characteristic of impurity-containing metals. This characteristic results, in general, in current testing results determined at a given temperature and strain rate deviating from the original properties of the specimens possessed before testing. The tensile testing results are mis-regarded as the original mechanical properties, forming a paradox in the tensile testing system.

During the elastic deformation stage of tensile testing, the changes in micro-structure occur at an atomic level, so that the concentration of impurity at grain boundaries and around dislocations varies with the time of elastic deformation. Different testing temperatures and strain rates induce different times of elastic deformation, leading to different impurity concentrations at grain boundaries and around dislocations, and therefore different mechanical properties. This is the underlying mechanism for the measurement uncertainty of mechanical properties in metals.

Based on the elastic deformation mechanism of the measurement uncertainty of tensile testing results, a new technology system for tensile testing is proposed by using a curve of "mechanical property-tensile strain rate" at a given temperature to characterize the original mechanical property, the service mechanical property, and the mechanical property during processing deformation. For the first time, a relationship of one-to-one correspondence between micro-structure and macro-mechanical property is established.

Author Contributions: Conceptualization, investigation, writing—original draft preparation, T.X.; data treatment, writing-review and editing, S.S.; data treatment, K.W. All authors have read and agreed to the published version of the manuscript.

Funding: This work was supported by the National Natural Science Foundation of China (grant nos. 51871064 and 52071088).

Conflicts of Interest: The authors declare no conflict of interest.

\section{References}

1. ASTM International. ASTM E21-03a: Standard Test Methods for Elevated Temperature Tension Tests of Metallic Materials; ASTM: West Conshohocken, PA, USA, 2003.

2. International Standard. ISO 6892-2:2011(E): Metallic Materials_Tensile Testing_Part 2: Method of Test at Elevated Temperature, 1st ed.; International Organization for Standardization: Geneva, Switzerland, 2011.

3. Sun, D.S.; Yamane, T.; Hirao, K. Intermediate-temperature brittleness of a ferritic 17Cr stainless steel. J. Mater. Sci. 1991, 26, 689-694. [CrossRef]

4. Sun, D.S.; Yamane, T.; Hirao, K. Influence of thermal histories on intermediate temperature embrittlement of an Fe-17Cr alloy. J. Mater. Sci. 1991, 26, 5767-5769. [CrossRef]

5. Otsuka, M.; Horiuchi, R. Ductility Loss of Al-Mg Aloys at High Temperatures. J. Jpn. Inst. Met. 1984, 48, 688-693. [CrossRef]

6. Nowosielski, R.; Sakiewicz, P.; Mazurkiewicz, J. Ductility minimum temperature phenomenon in as cast CuNi25 alloy. J. Achiev. Mater. Manuf. Eng. 2006, 17, 93-196.

7. Xu, T.; Zheng, L.; Wang, K.; Misra, R.D.K. Unified mechanism of intergranular embrittlement based on non-equilibrium grain boundary segregation. Int. Mater. Rev. 2013, 58, 263-295. [CrossRef]

8. Xu, T.D. Intermediate Temperature Brittleness in Metal and Alloy: A Trouble in Materials Science for Over 100 Years. In 10000 Selected Problems in Sciences, Physics; Committee of 10000 Selected Problems in Sciences, Physics: Beijing, China, 2009 ; pp. 523-525.

9. Suzuki, H.G. Strain Rate Dependence of Cu Embrittlement in Steels. ISIJ Int. 1997, 37, 250-254. [CrossRef]

10. Xu, T.D.; Liu, Z.J.; Yu, H.Y.; Kai, W. Measurement uncertainty of metallic ductility in tensile tests: Intermediate temperature embrittlement and strain rate embrittlement. Acta Phys. Sin. 2014, 63, 228101.

11. Nagasaki, C.; Aizawa, A.; Kihara, J. Influence of manganese and sulfur on hot ductility of carbon steels at high strain rate. ISIJ Int. 1987, 27, 506-512. [CrossRef] 
12. Kumar, K.S.; Pang, L. Effect of temperature and strain rate on the mechanical properties of Fe-40Al-0.6C. Mater. Sci. Eng. A 1998, 258, 153-160. [CrossRef]

13. Kraai, D.A.; Floreen, S. The hot ductility of nickel. Trans. AIME 1964, 230, 833.

14. Liu, C.M.; Abiko, K.; Tanino, M. Relation between the intergranular segregation of $S$ and the hot ductility in high purity Fe-S alloys. Acta Metall. Sin. (Engl. Lett.) 1999, 12, 637-644.

15. Horikawa, K.; Kuramoto, S.; Kanno, M. Intergranular fracture caused by trace impurities in an Al-5.5 mol\% Mg alloy. Acta Mater. 2001, 49, 3981-3989. [CrossRef]

16. Nachtrab, W.T.; Chou, Y.T. High temperature ductility loss in carbon-manganese and niobium-treated steels. Metall. Trans. A 1986, 17, 1995-2006. [CrossRef]

17. Xu, T.; Yu, H.; Liu, Z.; Zheng, Z. The measurement uncertainty of reduction in area of metals in tensile testing system. Measurement 2015, 66, 1-9. [CrossRef]

18. Xu, T.D. Interfacial Segregation and Embrittlement. In Reference Module in Materials Science and Materials Engineering; Hashmi, S., Ed.; Elsevier: Oxford, UK, 2016.

19. Guan, X.J.; Shi, F.; Ji, H.M.; Li, X.W. A possibility to synchronously improve the high-temperature strength and ductility in face-centered cubic metals through grain boundary engineering. Scr. Mater. 2020, 187, 216-220. [CrossRef]

20. Xu, T.D. A model for intergranular segregation/dilution induced by applied stress. J. Mater. Sci. 2000, 35, 5621-5628.

21. $\mathrm{Xu}$, T.D. Kinetics of non-equilibrium grain-boundary segregation induced by applied tensile stress and its computer simulation-ScienceDirect. Scr. Mater. 2002, 46, 759-763. [CrossRef]

22. $\mathrm{Xu}$, T.D. Creating and destroying vacancies in solids and non-equilibrium grain-boundary segregation. Philos. Mag. 2003, 83, 889-899.

23. $\mathrm{Xu}, \mathrm{T} . \mathrm{D}$. Grain-boundary anelastic relaxation and non-equilibrium dilution induced by compressive stress and its kinetic simulation. Philos. Mag. 2007, 87, 1581-1599. [CrossRef]

24. Shinoda, T.; Nakamura, T. The effects of applied stress on the intergranular phosphorus segregation in a chromium steel. Acta Metall. 1981, 29, 1631-1636. [CrossRef]

25. Song, S.H.; Wu, J.; Wang, D.Y.; Weng, L.Q.; Zheng, L. Stress-induced non-equilibrium grain boundary segregation of phosphorus in a Cr-Mo low alloy steel. Mater. Sci. Eng. A 2006, 430, 320-325. [CrossRef]

26. Misra, R. Issues concerning the effects of applied tensile stress on intergranular segregation in a low alloy steel. Acta Mater. 1996, 44, 885-890. [CrossRef]

27. Xu, T.D.; Cheng, B.Y. Kinetics of non-equilibrium grain-boundary segregation. Prog. Mater. Sci. 2004, 49, 109-208. [CrossRef]

28. Zheng, Z.W.; Xu, T.D.; Wang, K.; Shao, C. Progress in the theory of grain boundary anelastic relaxation. Acta Phys. Sin. 2012, 61, 246202.

29. Xu, T.D. Kinetics of Non-Equilibrium Grain-Boundary Segregation and Intergranular Fracture (Mechanism of Measurement Uncertainty); Science Press: Beijing, China, 2017.

30. Cadel, E.; Launois, S.; Fraczkiewicz, A.; Blavette, D. Investigation of boron-enriched Cottrell atmospheres in FeAl on atomic scale by three-dimensional atom-probe field-ion microscopy. Philo. Mag. Lett. 2000, 80, 725-736. [CrossRef]

31. Xiao, H.; Baker, I. The temperature dependence of the flow and fracture of Fe-40Al. Scr. Metall. Mater. 1993, $28,1411-1416$. [CrossRef]

32. Klein, O.; Baker, I. The effect of boron on the temperature dependence of the flow and fracture of Fe 45Al. Scr. Metall. Mater. 1994, 30, 1413-1417. [CrossRef]

33. $\mathrm{Wu}, \mathrm{D}$.; Baker, I. The effect of environment and strain rate on the room temperature tensile properties of FeAl single crystals. Intermetallics 2001, 9, 57-65. [CrossRef]

34. Xu, T.D.; Wang, M.Q.; He, H.M. Mechanical property-tensile strain rate curve of metals. Phys. Exam. Test. 2019, 37, 54-59.

35. Xu, T.D.; Yu, H.Y.; Wang, K.; Zheng, Z.W.; Gan, B. Uncertainty and Mechanical Properties Characterization of High Entropy Alloy in Tensile Testing. J. Iron Steel Res. 2020, 32, 909-925.

36. Xu, T.D. A discussion on measurement for original mechanical properties of tensile samples in metals. Phys. Exam. Test. 2021, in press.

37. Kobayashi, H. Hot-ductility recovery by manganese sulphide precipitation in low manganese mild steel. Trans. Iron Steel Inst. Jpn. 1991, 31, 268-277. [CrossRef]

38. Kizu, T.; Urabe, T. Hot ductility of sulfur-containing low manganese mild steels at high strain rate. ISIJ Int. 2009, 49, 1424-1431. [CrossRef]

39. Xu, T.D. Exchanging information with authors of 15 papers. Private Communications, 2020.

40. Lin, Z.Q.; Zheng, W.; Li, H.; Wang, D.J. Microstructures and mechanical properties of TA15 titanium alloy and graphene reinforced TA15 composites prepared by spark plasma sintering. Acta Metall. Sin. 2021, 57, 111-120.

41. Maciakowski, P.; Augustyniak, B.; Chmielewski, M.; Piotrowski, L. Application of mechanical Barkhausen noise in assessment of X20 steel properties after heat treatment. J. Electr. Eng. 2012, 63, 102-105.

42. Vourna, P.; Ktena, A.; Tsarabaris, P.; Hristoforou, E. Magnetic Residual Stress Monitoring Technique for Ferromagnetic Steels. Metals 2018, 8, 592. [CrossRef]

43. Hu, Z.B.; Fan, J.C.; Wu, S.N.; Dai, H.Y.; Liu, S.J. Characteristics of Metal Magnetic Memory Testing of 35CrMo Steel during Fatigue Loading. Metals 2018, 8, 119. [CrossRef] 
44. García-Martín, J.; Gómez-Gil, J.; Vázquez-Sánchez, E. Non-Destructive Techniques Based on Eddy Current Testing. Sensors 2011, 11, 2525-2565. [CrossRef]

45. Senkov, O.N.; Semiatin, S.L. Microstructure and properties of a refractory high-entropy alloy after cold working. J. Alloy. Compd. 2015, 649, 1110-1123. [CrossRef]

46. Laplanche, G.; Kostka, A.; Horst, O.M.; Eggeler, G.; George, E.P. Microstructure evolution and critical stress for twinning in the CrMnFeCoNi high-entropy alloy. Acta Mater. 2016, 118, 152-163. [CrossRef]

47. Senkov, O.N.; Wilks, G.B.; Miracle, D.B.; Chuang, C.P.; Liaw, P.K. Refractory high-entropy alloys. Intermetallics 2010, 18, 1758-1765. [CrossRef]

48. Lu, Z.P.; Lei, Z.F.; Huang, H.L.; Liu, S.F.; Zhang, F.; Duan, D.B.; Cao, P.P.; Wu, Y.; Liu, X.J.; Wang, H. Deformation behavior and toughening of high entropy alloys. Acta Metall. Sin. 2018, 54, 1553-1566.

49. Gludovatz, B.; Hohenwarter, A.; Catoor, D.; Chang, E.H.; George, E.P.; Ritchie, R.O. A fracture-resistant high-entropy alloy for cryogenic applications. Science 2014, 345, 1153. [CrossRef]

50. Senkov, O.N.; Scott, J.M.; Senkova, S.V.; Meisenkothen, F.; Miracle, D.B.; Woodward, C.F. Microstructure and elevated temperature properties of a refractory TaNbHfZrTi alloy. J. Mater. Sci. 2012, 47, 4062-4074. [CrossRef]

51. Senkov, O.N.; Wilks, G.B.; Scott, J.M.; Miracle, D.B. Mechanical properties of NbMoTaW and VNbMoTaW refractory high entropy alloys. Intermetallics 2011, 19, 698-706. [CrossRef]

52. Bishop-Moser, J.; Miracle, D. A call to action: High entropy alloy manufacturing. J. Mater. Res. 2018, 33, 2855-2856. [CrossRef]

53. Huo, W.; Hui, Z.; Feng, F.; Hu, X.; Xie, Z.; Jiang, J. Strain-rate effect upon the tensile behavior of CoCrFeNi high-entropy alloys. Mater. Sci. Eng. A 2017, 689, 366-369. [CrossRef] 